Journal of Business \& Management (COES\&RJ-JBM)

ISSN (E): 2306-7179 ISSN (P): 2306-8043

Publisher: Centre of Excellence for Scientific \& Research Journalism, COES\&RJ LLC

Online Publication Date \& Issue: 1st April 2017, Vol.5, No.2, April 2017

http://centreofexcellence.net/J/JBM/JBM\%20Mainpage.htm

\title{
The reality of human capital in the Algerian economic enterprise in the current economic transformations field study Sonelgaz Company - Unit Tlemcen - from 2000 to 2013
}

\author{
Dr. Mrs. Tafyani Almzdadh Boufateh Keltouma \\ College of Economic Sciences \\ University of Tlemcen \\ Algeria
}

\begin{abstract}
:
Most of the management systems currently use the concept of flexibility and organizational effectiveness aims to optimize the use of resources especially human resources to ensure a positive fit. For this, the company needs to make changes in terms of strategies and policies appropriate to its human capital.

Thus, the subject of this work is to bring some answers to the inability of the company to develop the skills and human resource investment performance despite endless efforts in management.
\end{abstract}

Keywords:

Investment in human capital, fees, change, strategy, performance evaluation.

\section{Citation:}

Koltouma, Tafyani Almzdadh Boufateh (2017, Importance of Business Incubators in Developing Entrepreneurial Ventures in Jordan; Journal of Business \& Management (COES\&RJ-JBM) Vol.5, No.2, pp.102-130. 
The reality in human capital.....

Résumé :

La plupart des systèmes de management utilisent actuellement la notion de flexibilité, et l'efficacité organisationnelle a comme objectif d'optimiser l'utilisation des ressources en particulier les ressources humaines pour assurer un ajustement positif. Pour cela,

L'entreprise doit faire des modifications en terme de stratégies et de politiques approprie à son capital humain.

Ainsi, l'objet de ce présent travail est d'apporté quelques éléments de réponse à l'incapacité de l'entreprise à développer les compétences et les performances des ressources humaines malgré les efforts infinis d'investissement en matière de gestion.

\section{Lesmotsclés :}

l'investissement dans le capital humain, les frais, changement, stratégie, évaluation de la performance.

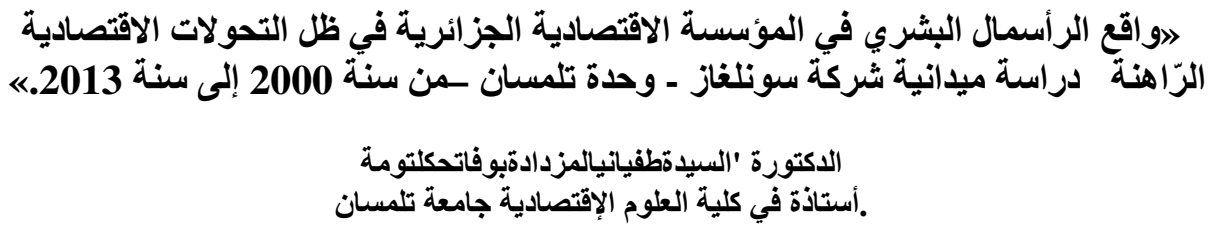

ملتصت معظمالنظم التسييرية نحو مفهوم المرونة والتحرر من القو الب الثابتة واصبحت الفعالية التنظيمية تتجدد بقدرة

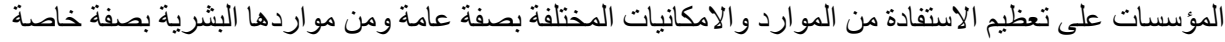

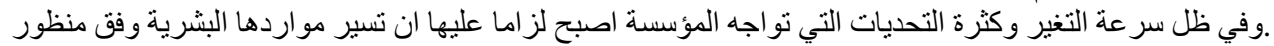

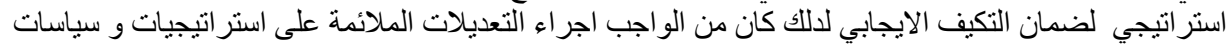

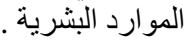

تهاف هده الدر اسة الى اظهار اشكالية استمر ارية سوء تسيير الموارد البشرية في المؤسسة الاقتصادية الجزائرية

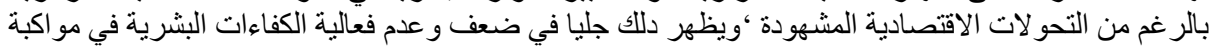

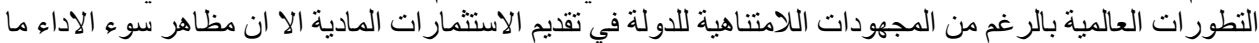

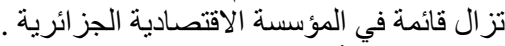
الكلماتالمفتاحية:الاستثمار في الر اسمال البشري ‘ائرية التكلفة، التغير، الاستر اتيجية، تقييم الاداء.

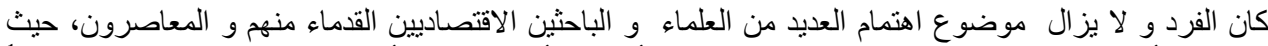

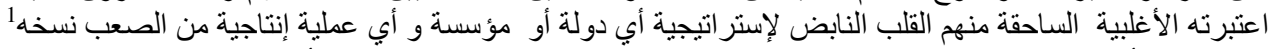

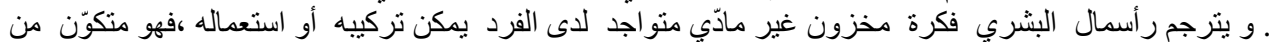

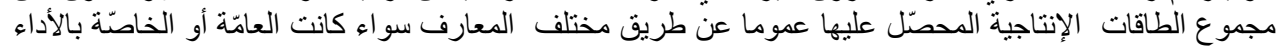

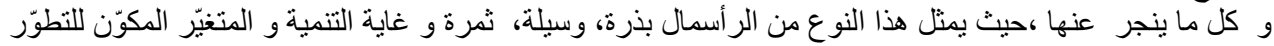
و و الفاعل فيه

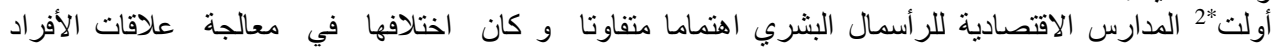

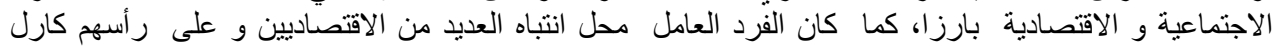

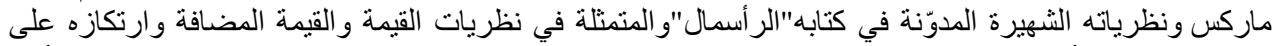

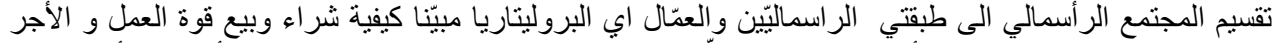

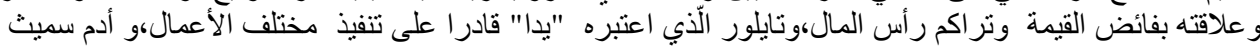

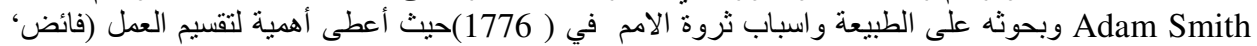

1 المورد البشري ، رأسمال المعرفي الاثمن في البلاد العربية ، محاضرة من إعداد مؤتمن عماد الدين شباط

" المدارس الاقتصادية: التجارية، الفزيوقر اطية ،الماركسية، الكلاسيكية، النيوكلاسيكية، الكينيزية 


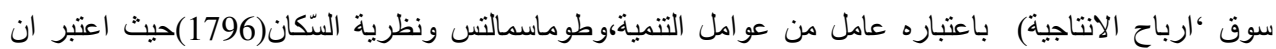

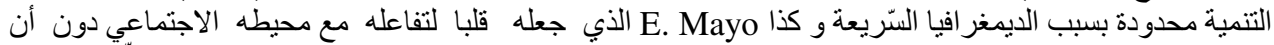

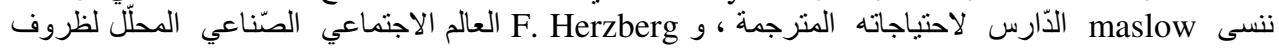

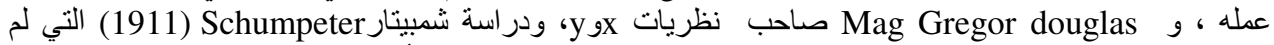

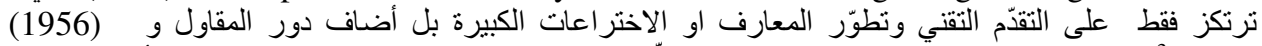

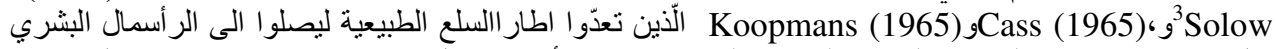

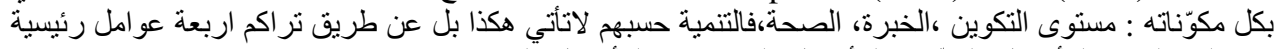

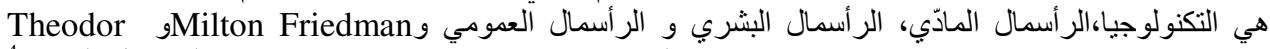
Schultz

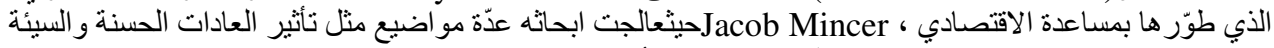

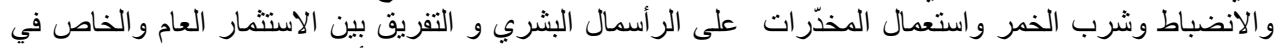

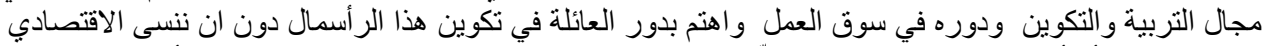

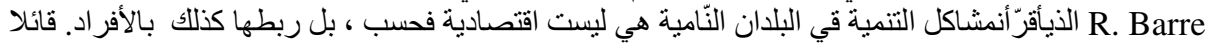

3ناب الر أس مال البشري سنة 1964 "A theoretical and empiricalanalysis": يقدم كأساس لتطوير فكرة

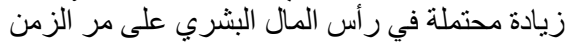

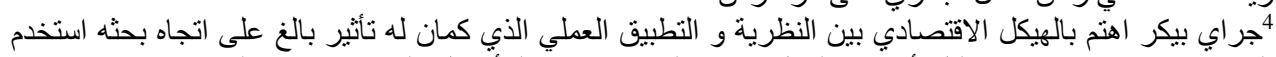

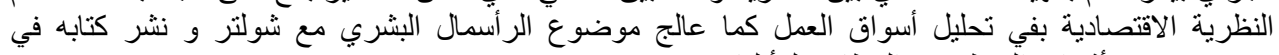
1957يتضمن تأثير ات التنوظيف و الوظائف للأفليات. 
«danslespays sous-développés‘lesproblèmes de développement ne sont pas seulement économiques ; ils sont encore et surtout humains». ${ }^{5}$

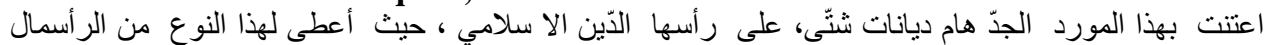

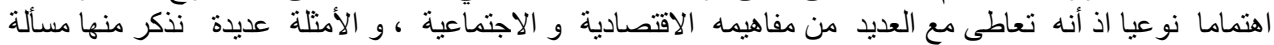

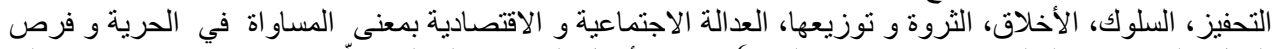

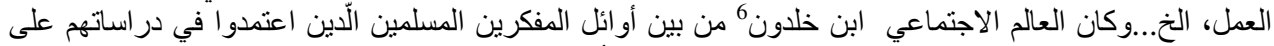

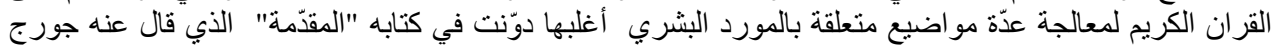

«l'œuvre d'Ibn Khaldoun est un des ouvrages les plus substantiels et les plus

Georges Marçais مارسعايز

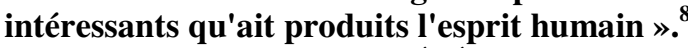
"إنمؤلفابنخلدونهو أحدأهمالمؤلفاتالتيانجز ها الفكر الإنساني".

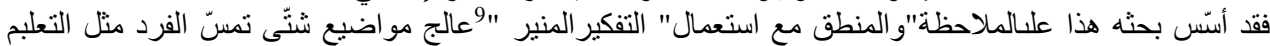

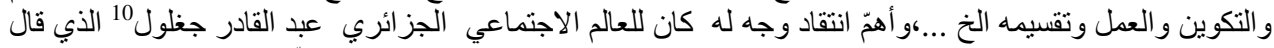

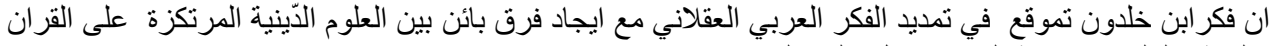

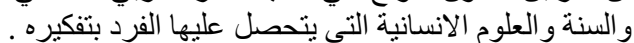

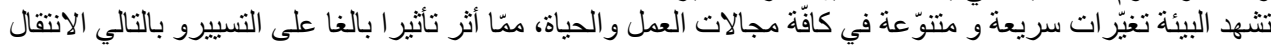

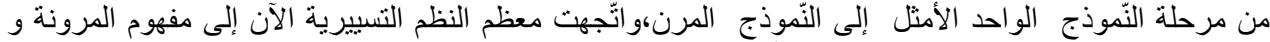

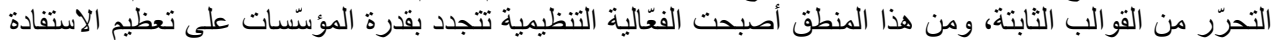

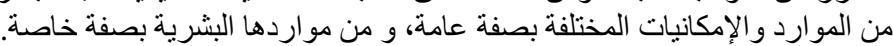

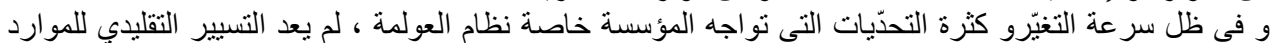

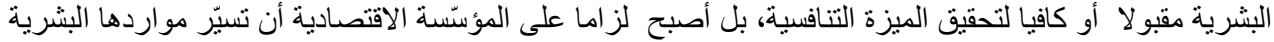

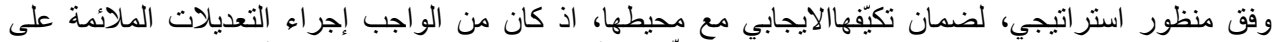

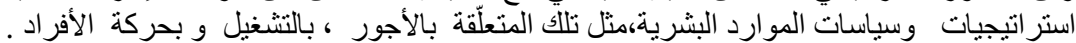

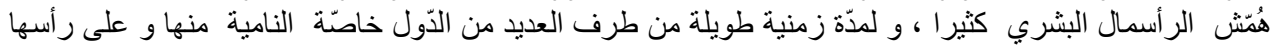

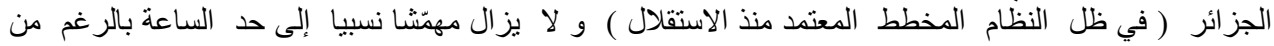

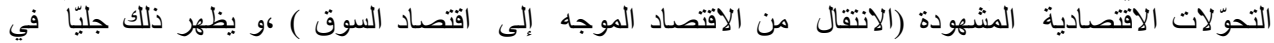

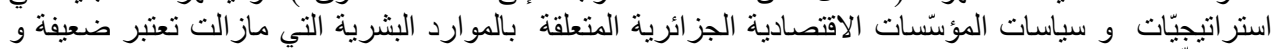

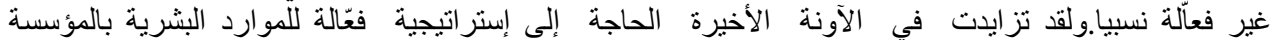

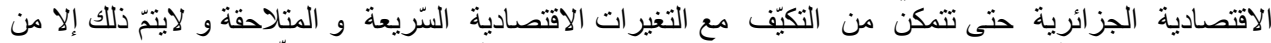

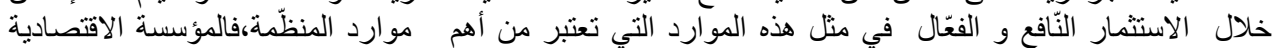

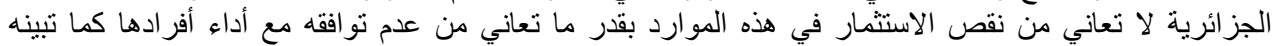
الاشكالية المطروحة. لائة

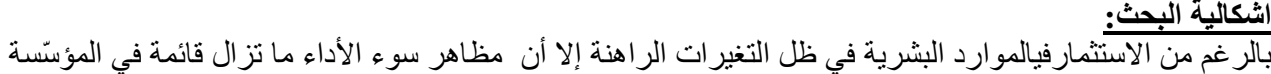

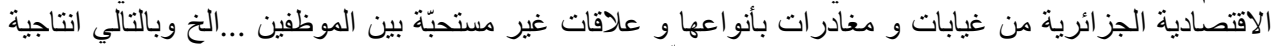

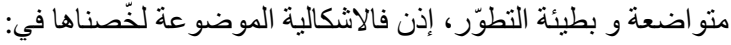

5 Investissements et Développement : Approche Systémique les communications ducoloque international : Evaluation des effets des programmes d'invetissements publics 2001-2014 et leurs retombées sur l'emploi, l'investissement et la croissance économique, Dr. Aoumeur AKKI ALOUANI Maître de conférences catégorie A Université de Sétif I, les $11 \& 12$ mars 2013

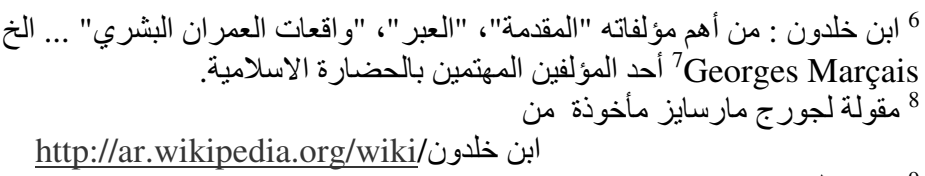

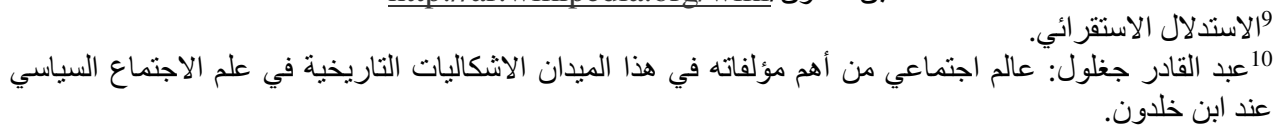




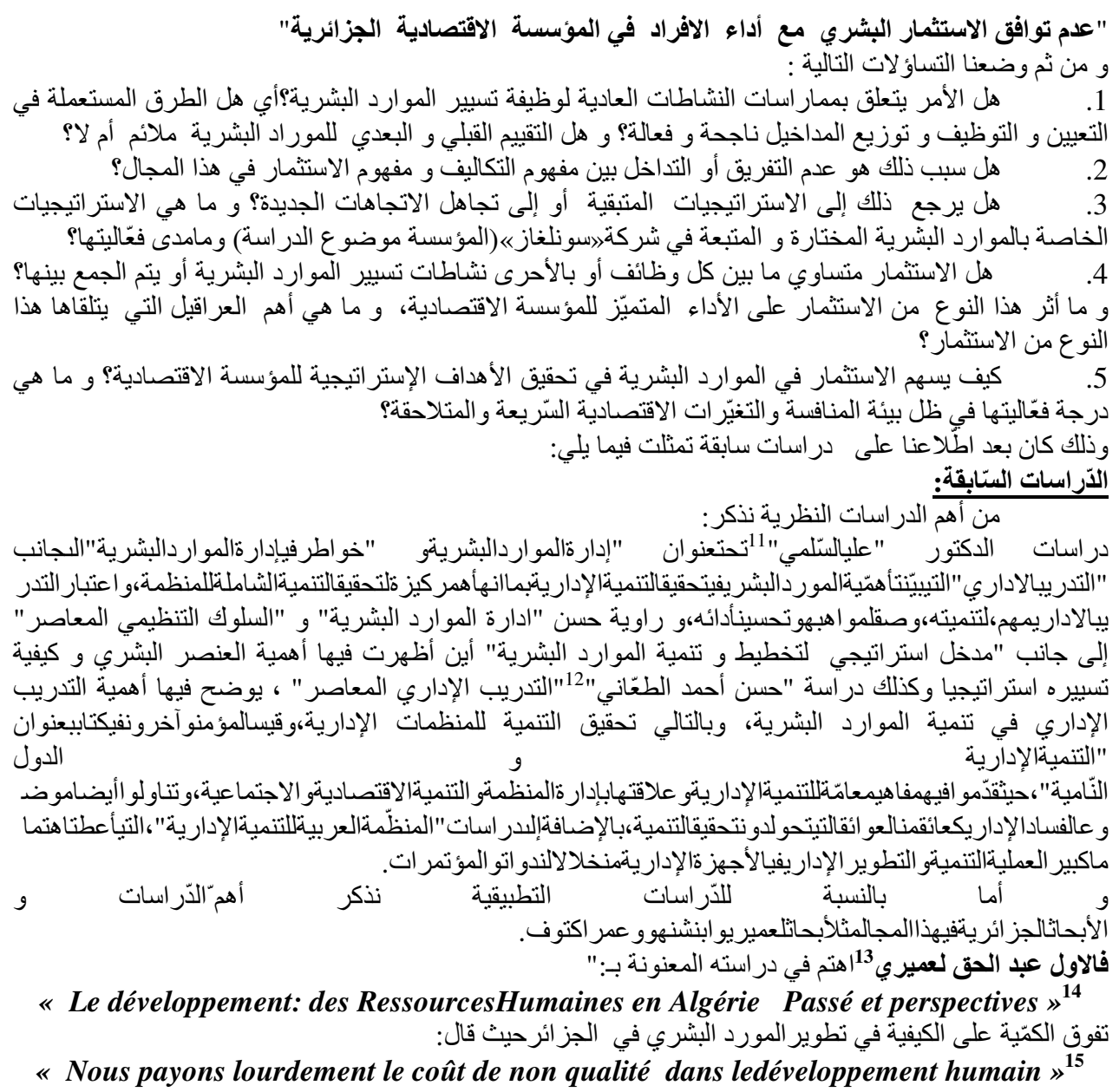

11 علي السلمي من مؤلفاته مايلي: مقدمة في العلوم السلوكية 1969، إدارة الأفر اد لرفع الكفاءة الإنتاجية 1970،

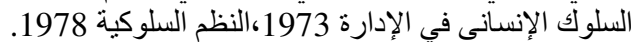

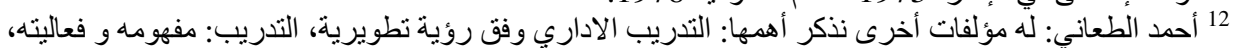
بناء البر امج التدريبية و الهو تقويمها. 13

Problématique du logement : Y a-t-il des espoirs de solutions ،2014/12/15 ، Le slogan «Mettrel'entreprise au cœur des politiqueséconomiques» est-iltrompeur‘2014/09/29 ، Le manager et le leader : Quellesleçons pour l'entreprisealgérienne ، 2014/09/22 ، HORIZONS

"sans l'intelligence on ne peut aller loin " 02/03/2015

« la décennie de la dernière chance: "emergence oudéchéance de من كتبه l'économieAlgérienne? » octobre 2013

${ }^{14}$ publié dans liberté 06/11/2013par said smati // http://www.djazairess.com/fr/liberte/209903

Abdelhak LAMIRI مرجع سابق15 


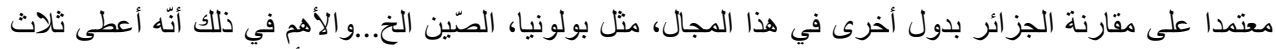

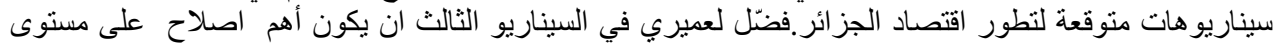

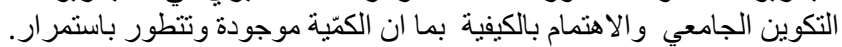

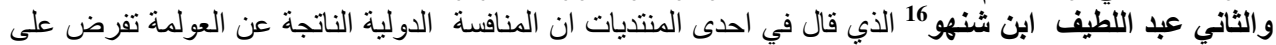

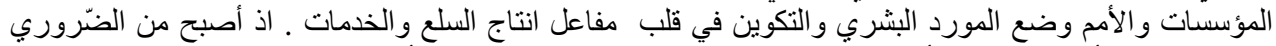

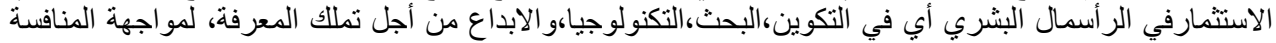

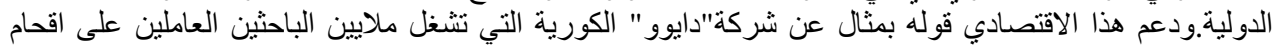

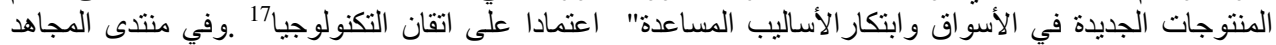

«Les pays émergents : le cas algérien».

المنعقد تحت عنوان:

أكد في اطار الاستثمار في الرأسمال البشري دائما، ضرورة القيام باصلاحات جدرية على المنظومة التربوية

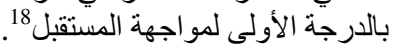
والثالث عمر اكتوفى 19 الذي قام بعدّة أبحاث من أهمّها در استه المشهورة

La "stratégie de l'autruche" Post-mondialisation ، management

حيث تكلّم الباحث عن تخلي المؤسّّات عن أولوية القيمة الاستعمالية لفائدة القيمة التبادلية ،وفي أحد فصول هذه

$$
\text { الدر اسة المعنون بـ: الباحث: }
$$

\section{"L'économie-management face à l'humanisme : entre l'employé ressource et l'employé} partenaire ${ }^{21 " \prime}$

يتساءلالمفكر عن مكانة الفرد في النظريات التسييرية الحديثة عموما ويعترف أن المؤسّّات لا تمكّن العاملين من أن أن أنسات

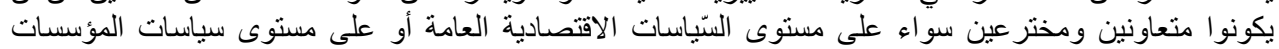

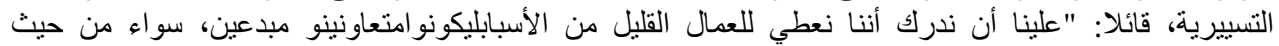

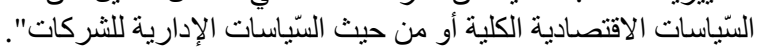

Il nous faut reconnaître que nous donnons peu de raisons aux travailleurs d'être coopératifs et créatifsautant en termes de politiques économiques globales qu'en termes de politiques managériales des entreprises.

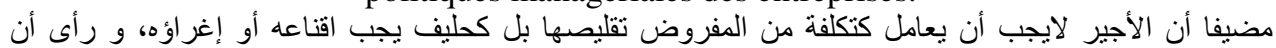

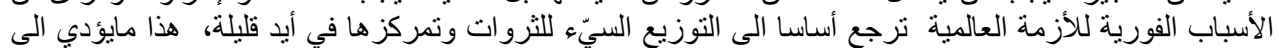

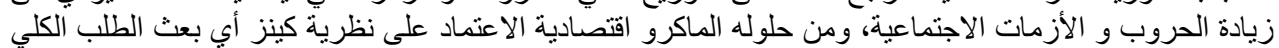

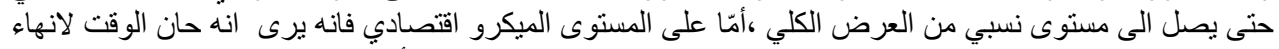

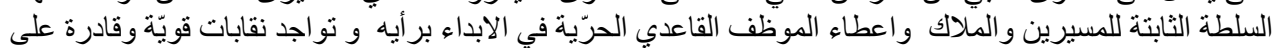

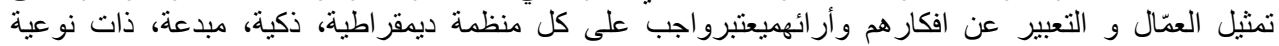

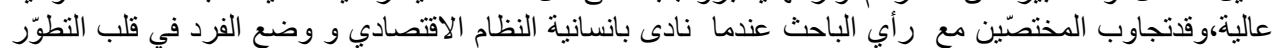

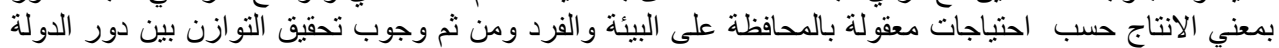
ودور المؤسسة في ذلك . ت التناج

16 أبرز مؤلفاته: "التجربة الجزائرية في التتمية و التخطيط"، "تكوّن التخلف في الجزائر"، "مدخل إلى الاقتصاد

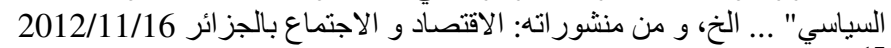

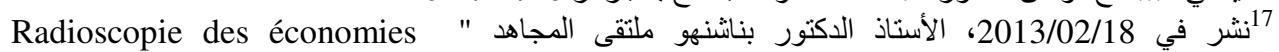
"émergentes

18 Publie le 17/02/2013 «Abdellatif Benachenhou: 'L'Algérie n'est pas un pays émergent',

http://www.algerie-focus.com/blog/2013/02/abdellatif-benachenhou-lalgerie-nest-pas-unpays-emergent/

$$
19 \text { كتاباته كثيرة و متنو عة من أهمها: }
$$

- Le management entre tradition et renouvellement, Gaétan Morin, 2006

- Post-mondialisation, management et rationalité économique, Eco société, 2002.

- Halte au gâchis ! En finir avec l'économie management à l'américaine, Liber, 2008.

- Le travail industriel contre l'homme, OPU-SNED, 1986La stratégie de l'autruche.

${ }^{21}$ Pr. Omar Aktouf, «LA STRATEGIE DE L'AUTRUCHE » editeurecosociété 08/2002 


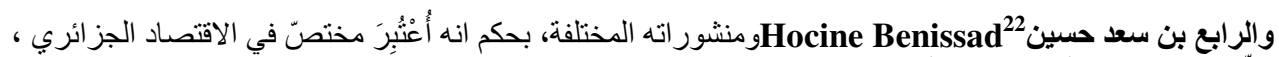

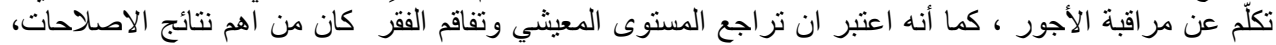

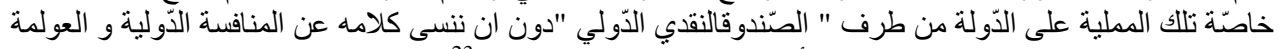

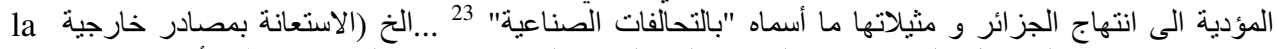

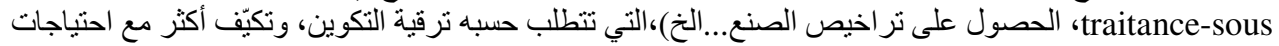
سوق العمل و الاحتفاظ بمو ارد بشرية مؤهلة هلة وذات خبرة العبرة.

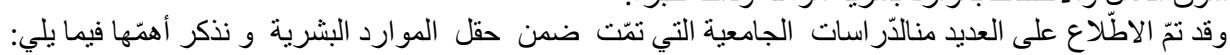

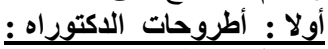

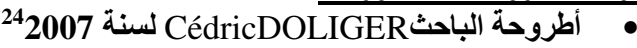

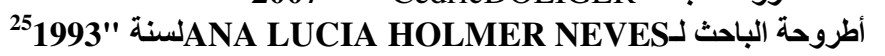

أطروحة الباحث أبروحة لسنة 2011 أطروحة برويقات لسنة 2009

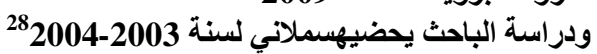

الى جانب أطروحة الباحثمسينير قيلينة 2007"

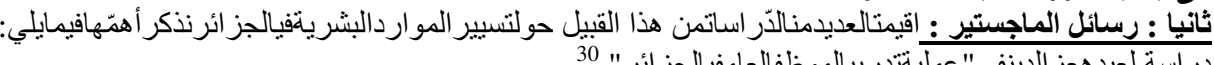

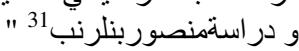
وفيالأخيربحث قريشي محمد الصنالحنب 32

22 حسين بن سعد: لله العديد من المؤلفات حول تطور تجربة الجزائر من التخطيط الاشتراكي إلى الإصلاحات الاقتصادية و من أهم كتبه:

- La reformeéconomique en Algérie

- Economie du développement de l'Algérie 1692 1978

${ }^{23}$ Houcinebenisaad «Les recommandations du FMI n'expriment que ses propres opinions » Publié dans El Watan le 27/03/2006 par AkliRezoualihttp://www.djazairess.com/fr/elwatan/39148

${ }^{24}$ Thèses de doctorat,de l'Université de Strasbourg " Démographie, fécondité et croissance économique en France: une analyse cliométrique"DOLIGER, Cédric (2006); Université Louis Pasteur12 Janvier 2007

${ }^{25}$ «L'entreprise et la gestion des ressources humaines en france (et comparaison avec le bresil) »par ANA LUCIA HOLMER NEVES Thèse de doctorat en Droit privé Sous la direction de M-FRANCE MIALON. Soutenue en 1993Paris

${ }^{26}$ Thèse de doctorat"On the impact of education on human capital depreciation, wage growth, and Tenure"WEBER, sylvain2011 Univ. Genève le role attendu des professionnels RH lors d'un changement organisationnel" Martine risinand

HEC Montrèal affiliée à l'université 2003e montreal

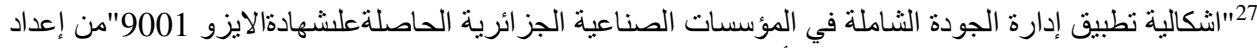

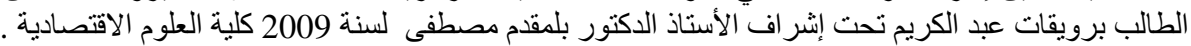

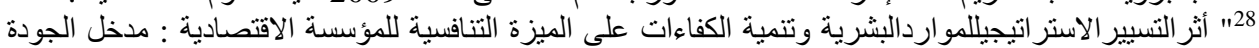

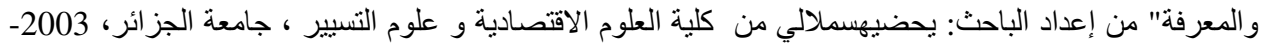

29" استر اتيجية تنمية الموارد البشرية في المؤسسة الاقتصادية حالة مؤسسة "سونطر اك" سنة 2007" من إعداد إلاد

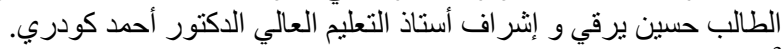

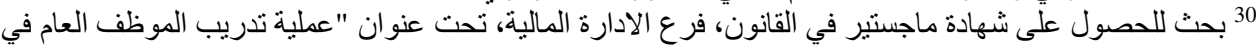

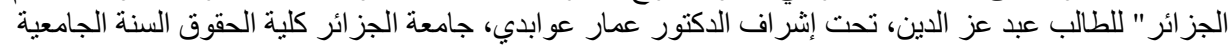
$2002-2001$ والإ. د. بلرنب منصور، الإصلاح الإداري و البيروقر اطية في الجزائر، بين النظرية و النطبيق، معهد العلوم السياسية و الإعلام، الجزائر، 1982 
The reality in human capital.....

و من ثم وضعنا الفرئ : الفرضيات التالية:

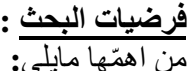

التشبّت بالطرق التقليدية و بعض الممارسات السيئة في تسيير الموارد البشرية التي تؤثر سلبا على أداء الأفراد داخل

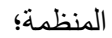

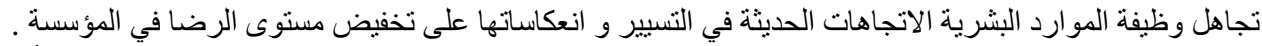

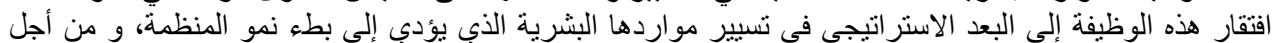

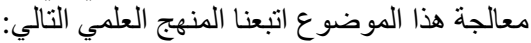

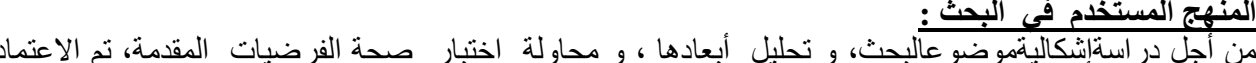

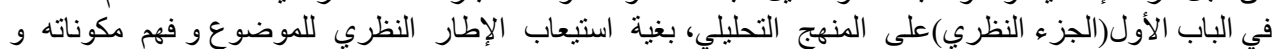

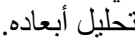

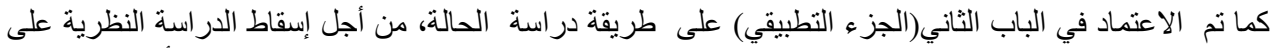

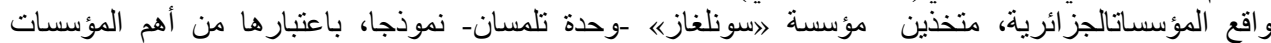

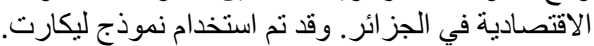

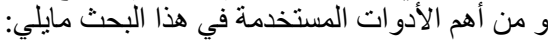

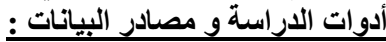

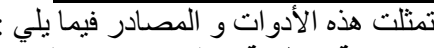

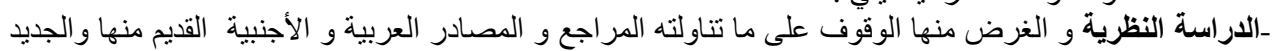

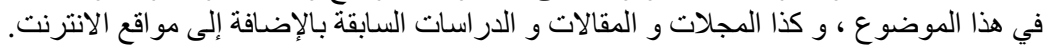

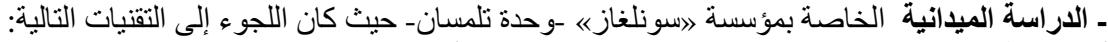

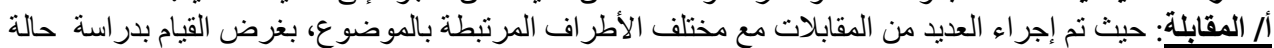

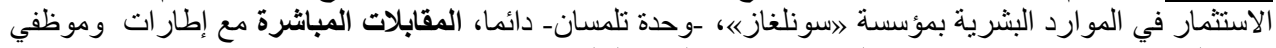

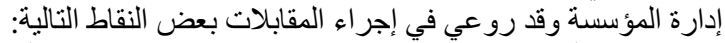

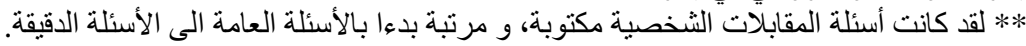

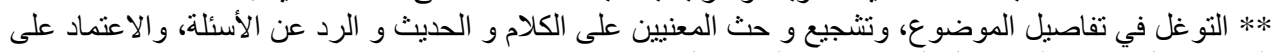

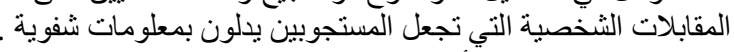

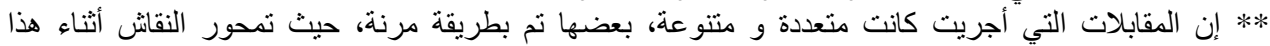
الموضوع حول الموضوع محل الدراسة بصورة عامة، و هذا ما شجع المستجوبين على التعبير عن أفكار هم بحرية

كاملة. ب / التقارير و الإحصائيات: التي تم الحصول عليها من مختلف الأقسام و المصالح.

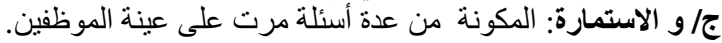
و الدراسة كانت لها حدود نمثلت فيما يلي:

حدود الدراسة:

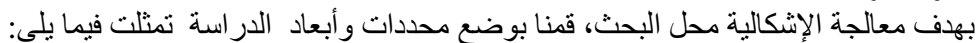

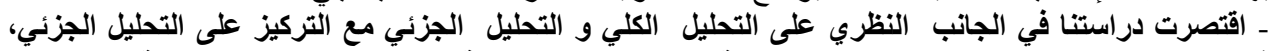

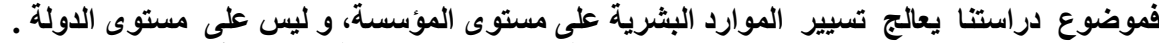

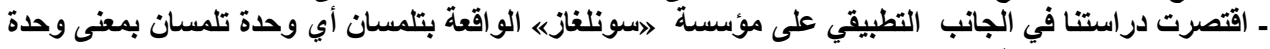

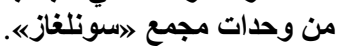

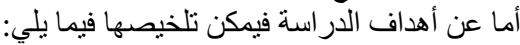

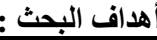

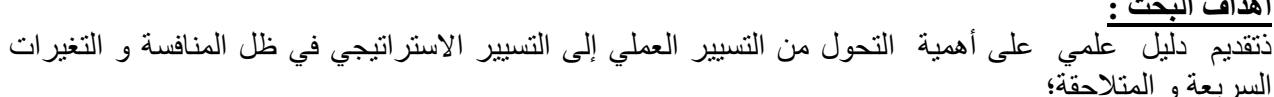

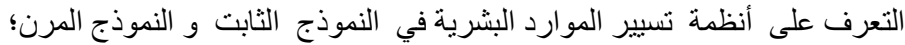

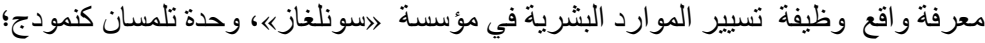

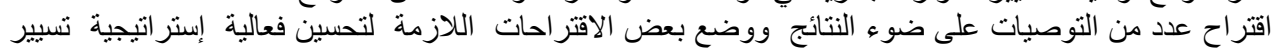

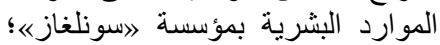

32 من إعداد الطالب: قريشي محمد الصالح وتحت إثر اف الأستاذ بوخمخ معبد الفتاح، جامعة منتوري - قسنطينة ـ 
و نطمح في الأخير من خلال هذا البحث إلى إضافة لبنة جديدة تضاف الى مجموعة البحوث و الدراسات المتعلقة

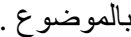
أهمبة البحث : البرغ

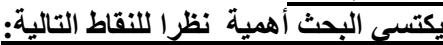

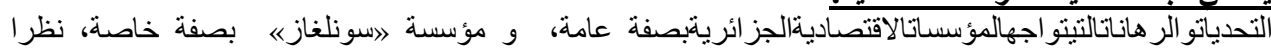

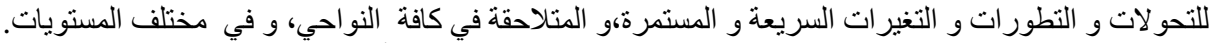

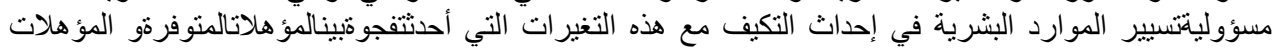

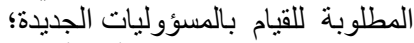

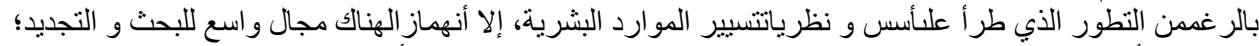

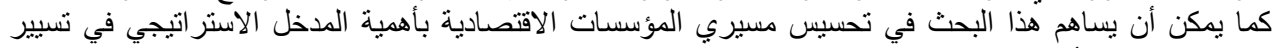

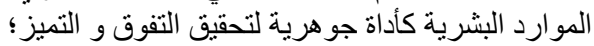

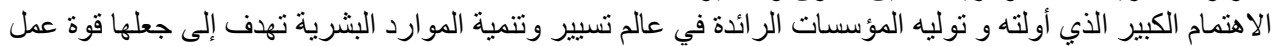

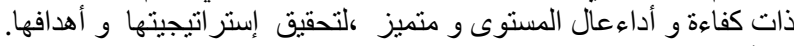

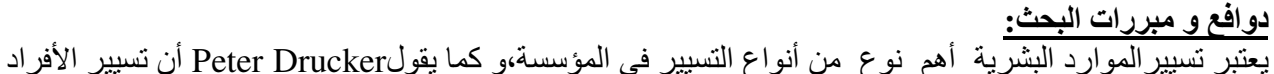

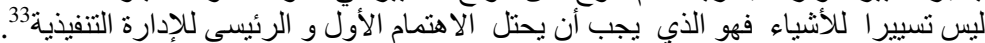

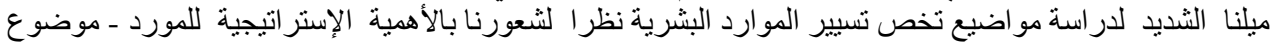

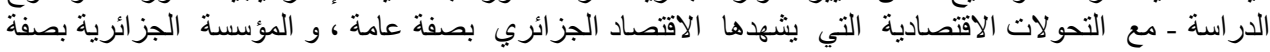

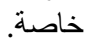

المكانة و الأهمية التي تتمتع بها مؤسسة 》سونلغاز 《 بالنسبة للاقتصاد الوطني، حيث تعتبر مصدر رزق للعديد من العمال الجزائربين. نشاط هذه المؤسسة لله علاقة متينة متينة مع بعض سياسات الدولة ، مثنلا سياسة التعمير (الإسكان، و التجهيز

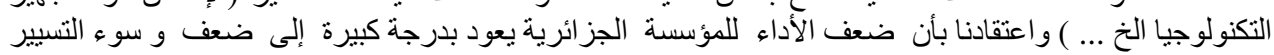

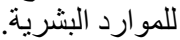

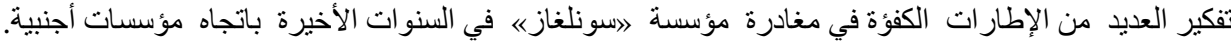

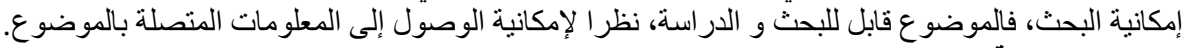

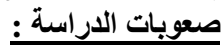

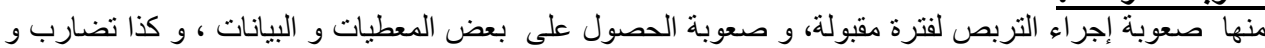

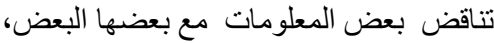
تقسيمات البحث و مشتملاته :

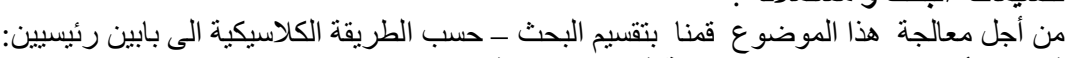
فالباب الأول: (النظري) ضمناه الرئاه سبعة فصول تمثلت في:

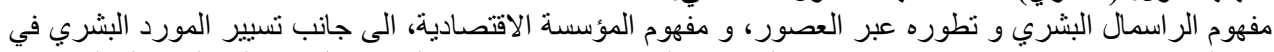

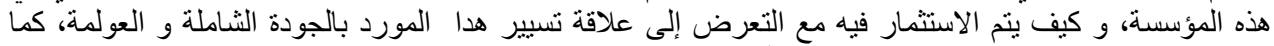

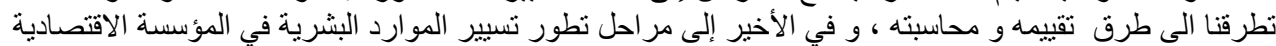

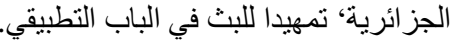

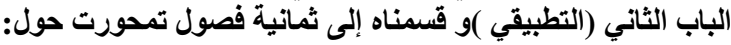

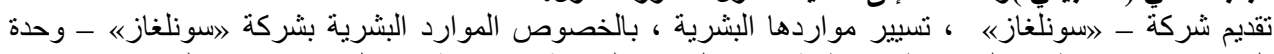

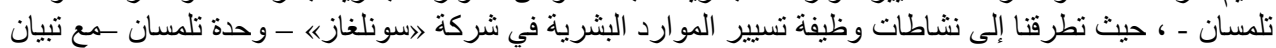

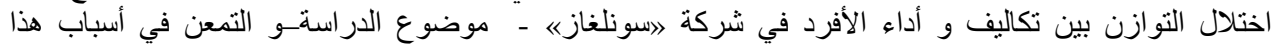

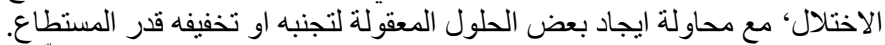

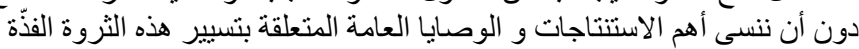

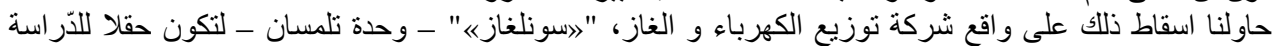

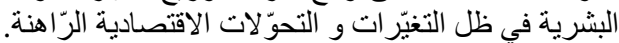

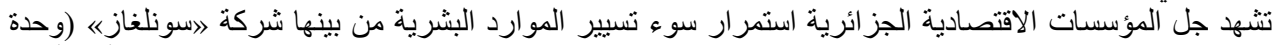

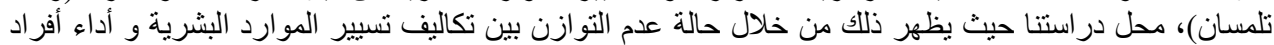
الثركة المعنية و من ثم كانت اشكاليتنا مطروحة دلثن فلى النحو التالي:

${ }^{33}$ Peter drucker, tasks responsabilités,practices, london, heinemann ;1974,p41. 
The reality in human capital.....

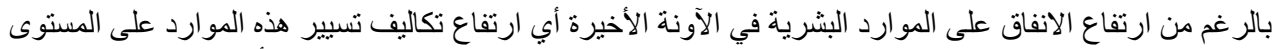

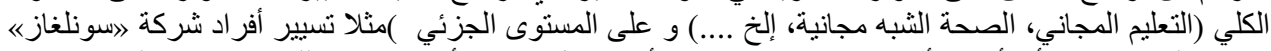

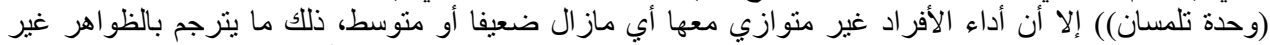

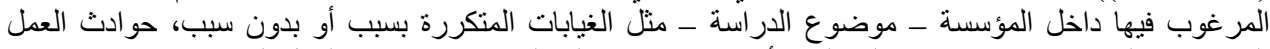

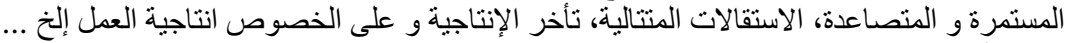

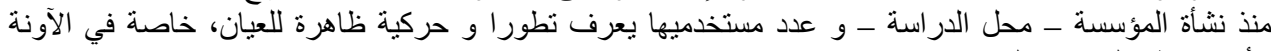
الأخيرة نظر التوسعهاة المستمر التسن.

المصدر:وثائق المؤسسة الداخلية مع الاعداد الثخصي 2010

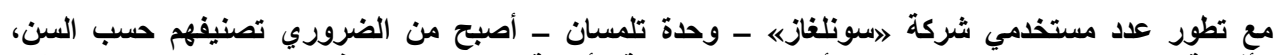

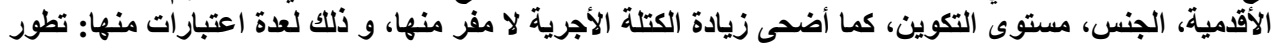
عدد المستخدمين.

المصدر: وثائق المؤسسة الداخلية مع الاعداد الثخصي2011

أ. تطور تكاليف الأفراد عرفت تكاليف الموظفين في مؤسسة 》سونلغازه تطورا ملحوظا من 2007 إلى المالى 2009، كما تبينه الأشكال و الجداول تكالف الموالية:

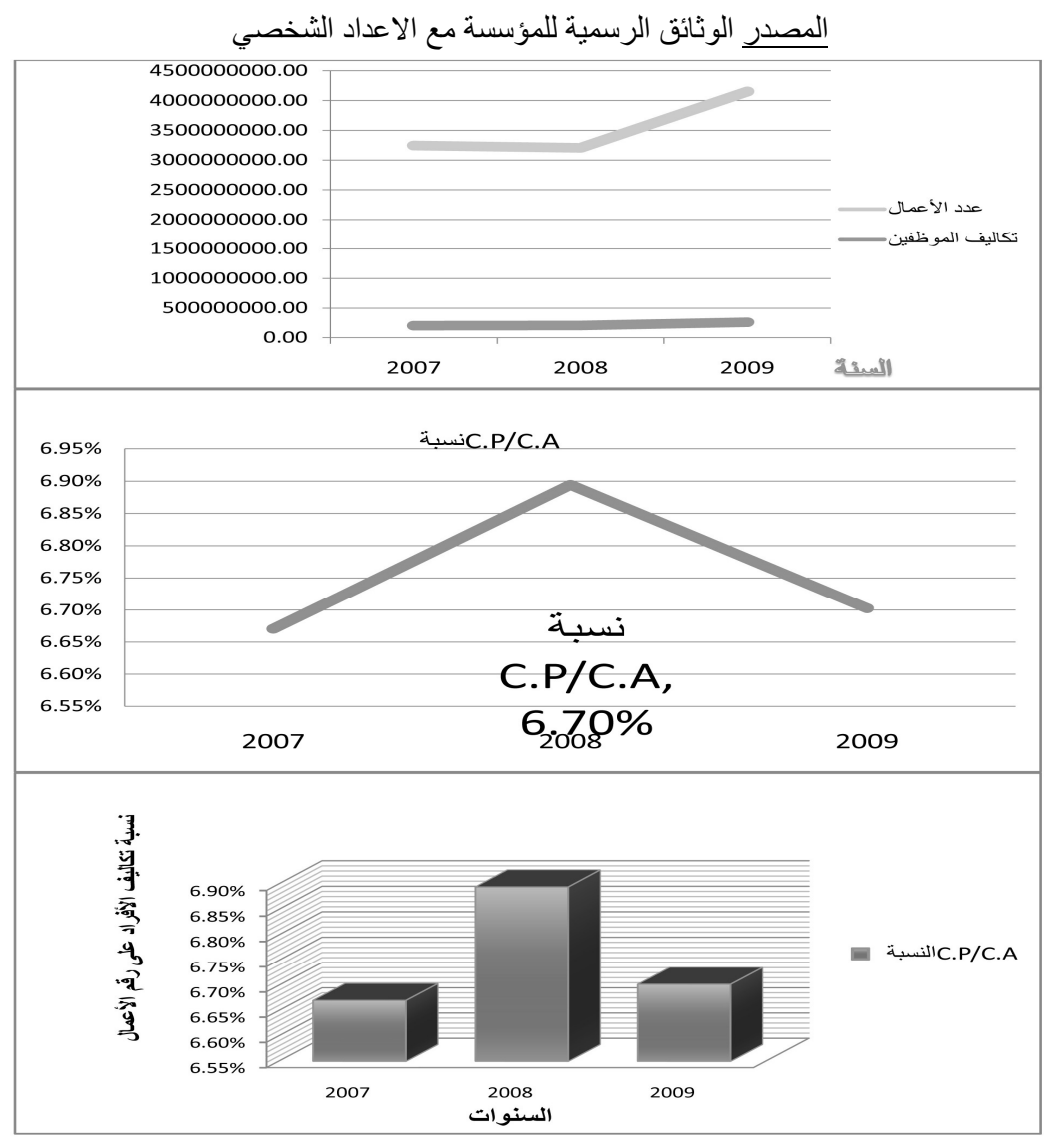




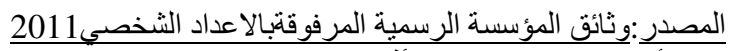

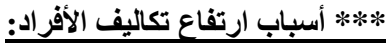

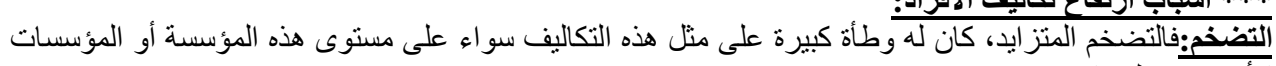
الأخرى في لجز ائر؛

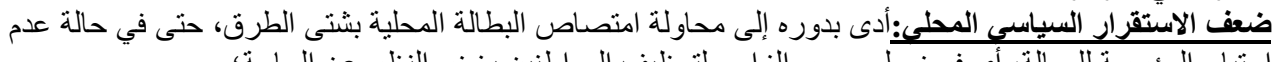

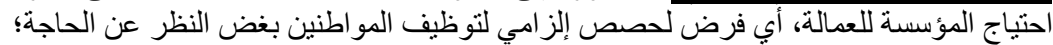

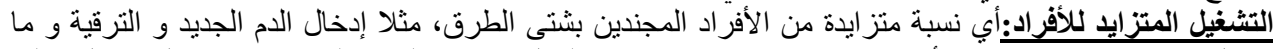

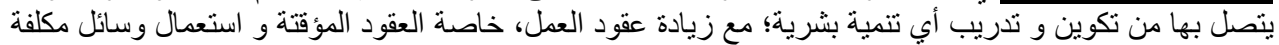

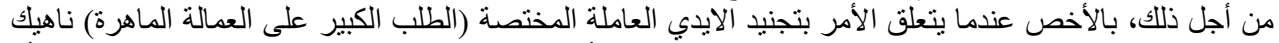

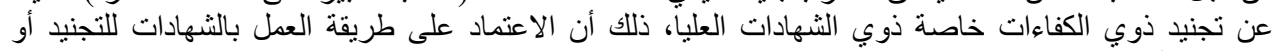

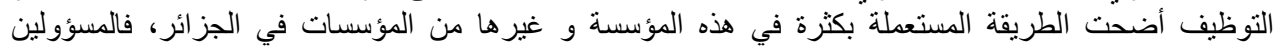

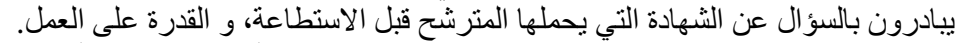

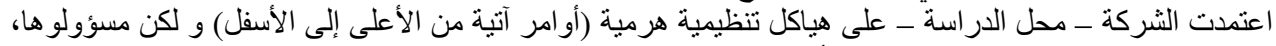

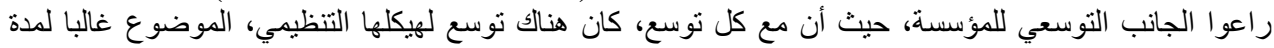

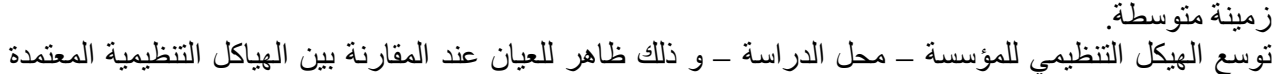

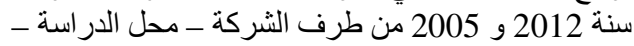
إذا ما فسرنا تطور نسبة تكاليف الأفراد من رقم الأعمال خلال فترة 2007، 2009 في مؤسسة 》سونلغاز 《) (وحدة تلمسان). نجد أن سنة 2008، مثلت أعلى نسبة، نظر الارتفاع تكاليف العمال و انخفاض رقم الاعمال.

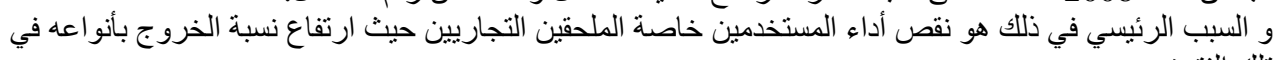
تلك الفترة. هذا ما يجرنا إلى التكلم عن ضعف أداء المستخدمين بالر غم من زيادة التكاليف

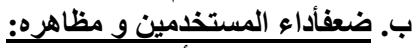

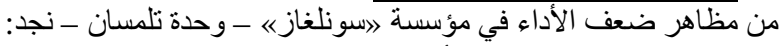

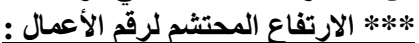

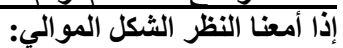

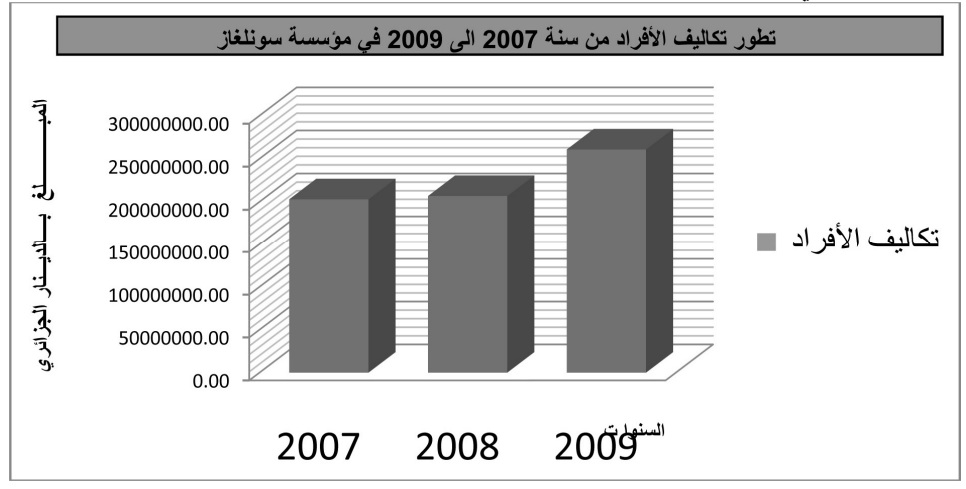

المصدر: الوثائق الرسمية للمؤسسة ـقسم المالية_مع الاعداد الثخصي2011

نجد أن ارتفاع رقم الأعمال في شركة 》سونلغاز《 (وحدة تلمسان) تطور بمستويات محتشمة منذ 2007 إلى 2009

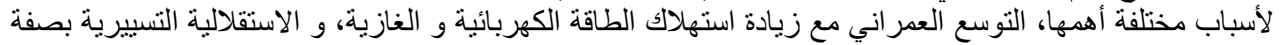

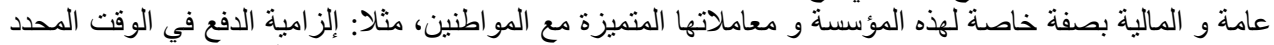

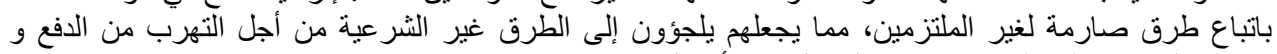

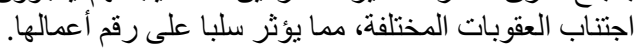

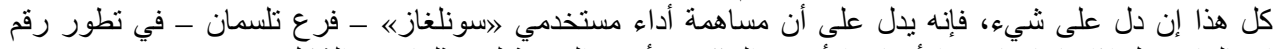
اعمالها ضئيل إذا ما قارناه مع الأسباب الأخرى المذكورة أعلاه المسبية لله، مثلما يبينه الثكل. 
The reality in human capital.....

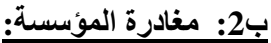

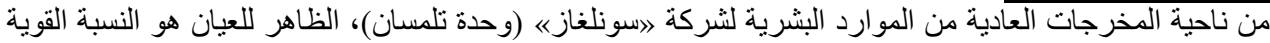

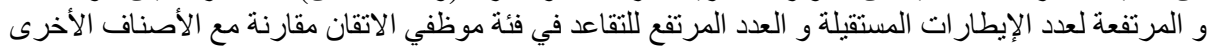

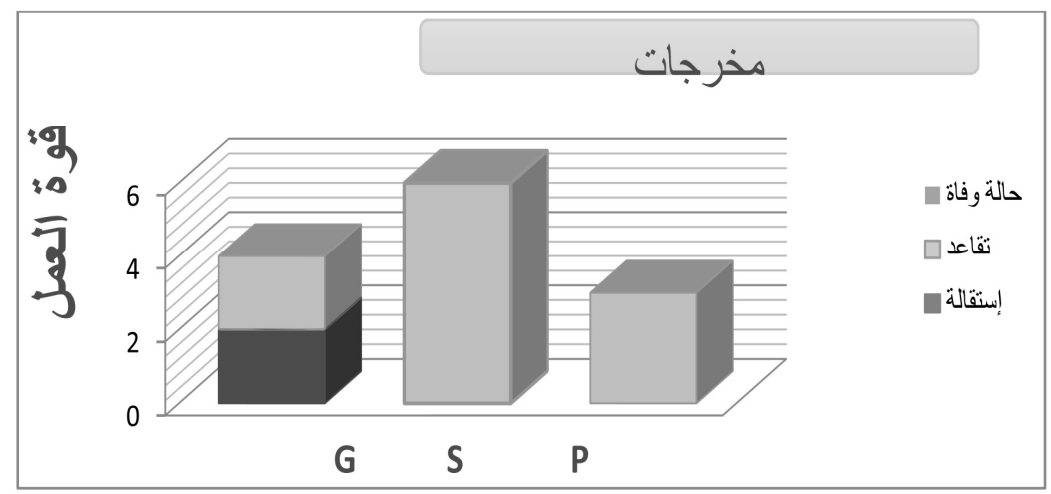

المصدر: وثائق المؤسسة الداخلية مرفوقةبالاعداد الثخصي2012

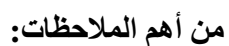

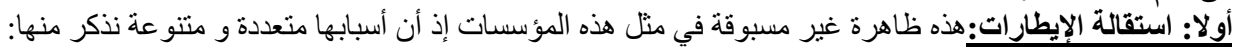

1-1

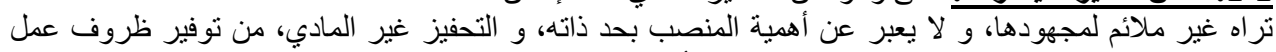

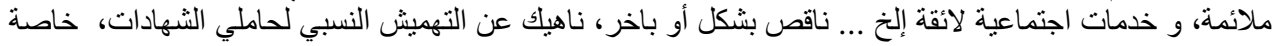

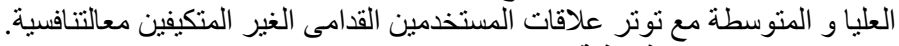

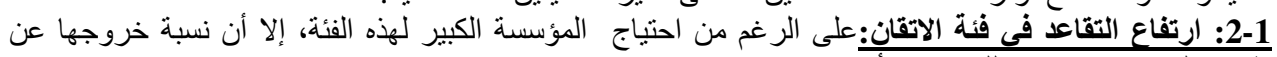

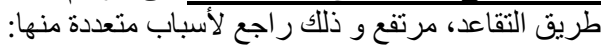

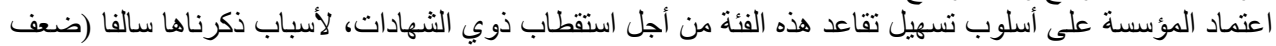

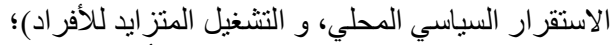

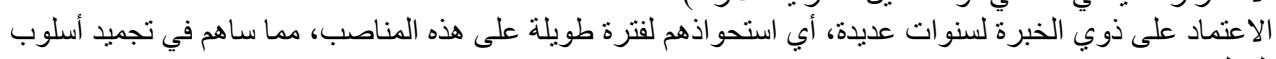
عدم تجاوب هؤ لاء مع تغيرات المؤسسة ـ محل الدراسة - (استقلالية تسييرية، مالية)، و مع البيئة الجديدة المنطلبة لتقنيات منطورة. ب3: التغيب عن العمل: إذا نظرنا إلى مجمل الغيابات، حسب الثكل الموالي

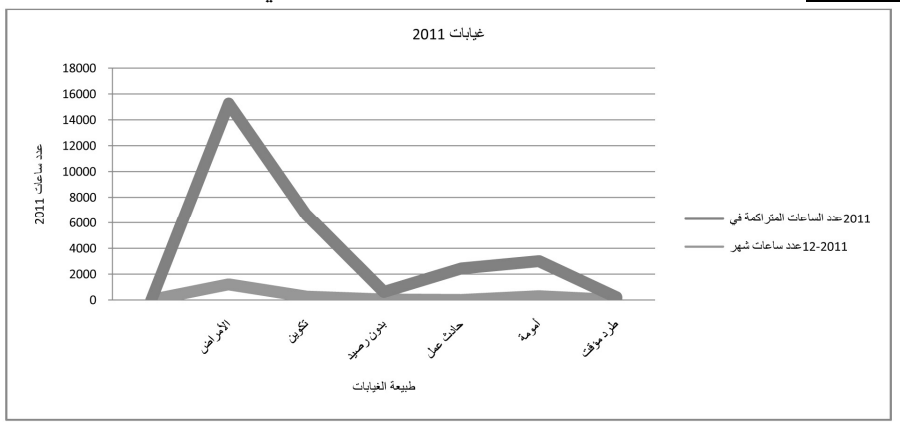

المصدر: الاعدادالثخصي بالاستعانة بالوثائق الرسمية للمؤسسة 2012 
نجد أن:

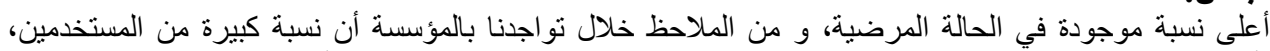

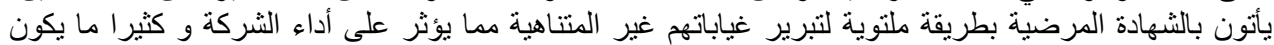

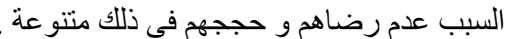

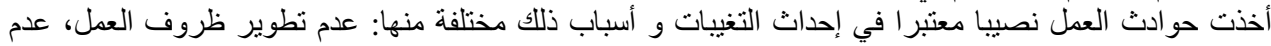

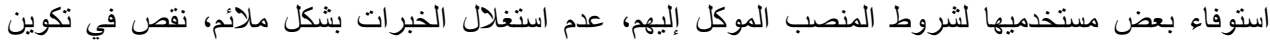

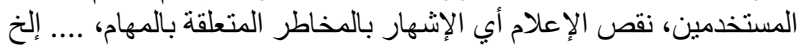

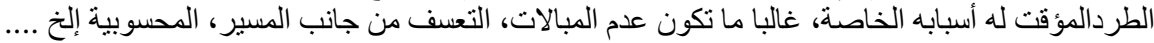

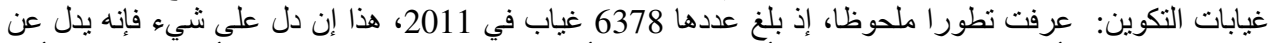

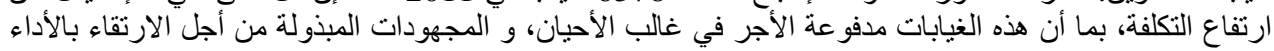

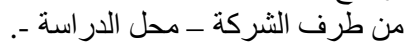

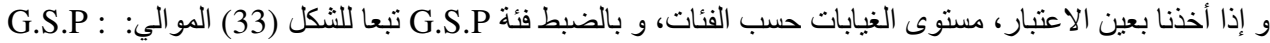
groupes sociaux professionnels

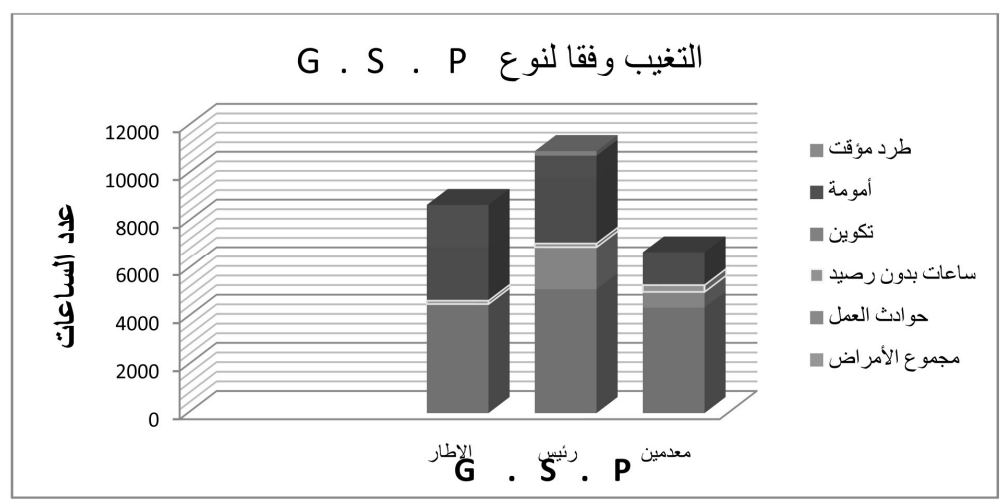

المصدر:وثائق المؤسسة الرسمية مع الاعداد الثخصي 2012

يمثل الغياب بسبب أمر اض قصيرة المدى أعلى نسبة في صفوف الإطار اته، فالرقم الرسمي لا يعبر غالبا عن حقيقة

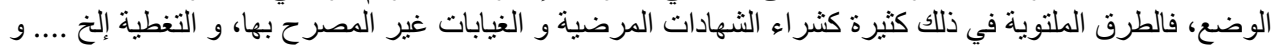

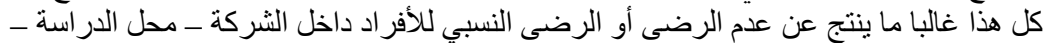

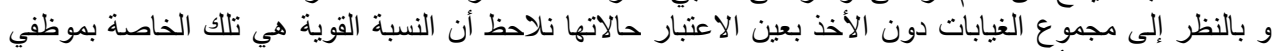

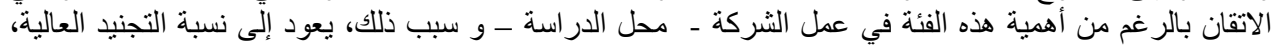
الموجودة في هذه الفئة مقارنة مع الفئة الفئات الفئ الأخرى.

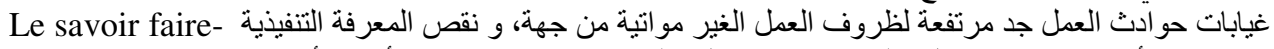

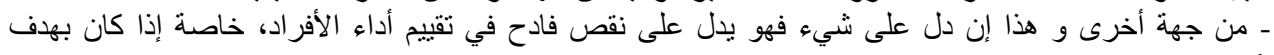
تكوينه. غيابات التكوين: كانت مرتفعة أكثر في صفوف موظفي الاتقان، من أجل التأقلم مع التقنيات الجديدة ذللك ما يترجم

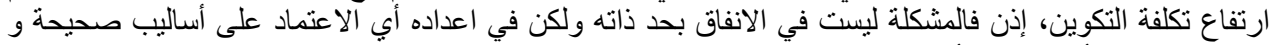

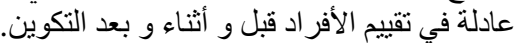

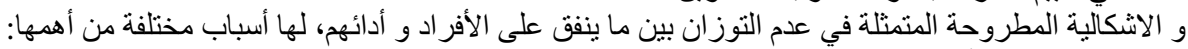

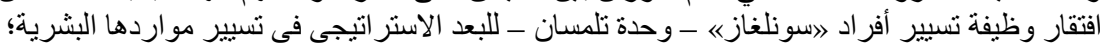

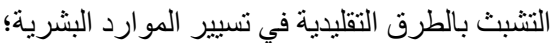

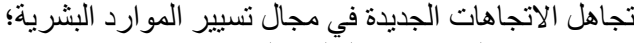

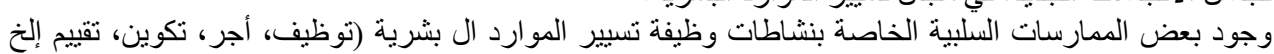

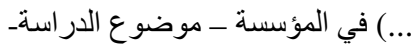

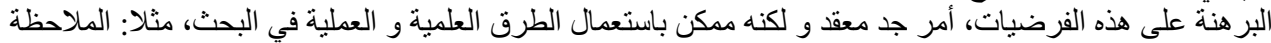

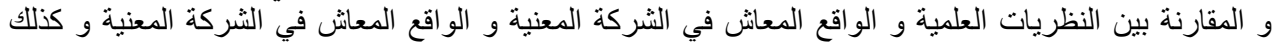


The reality in human capital.....

الاستقصاء بو اسطة ما يعرف الاستمارة أي طرح أسئلة شفهية و كتابية، مباشرة و غير مباشرة مغلقة و مفتوحة على مستخدمي هذه الأخيرة. ذلك ما استخدمناه من أجل معالجة هذه الاشكالية و وأسبابها أي فرضياتها

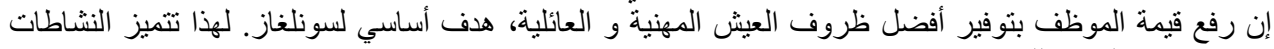

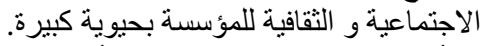
إلا أن ذللك، كان بعيد المنال، نتيجة أسباب.

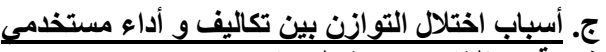

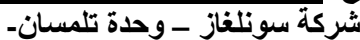

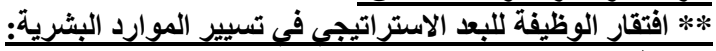

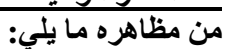

عدم رقاء تكاليف الموارد البشرية أو الر أسمال البشري إلى أصل استيراتيجي مثله مثل الأصول المادية الاخرى أو

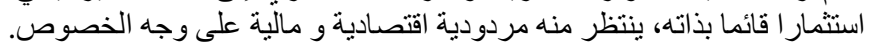

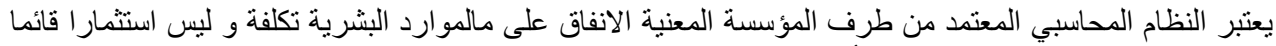

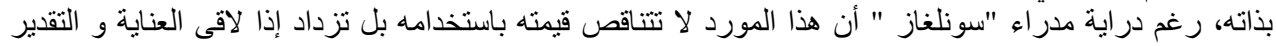
النازم.

يجد مسؤولي الشركة صعوبة في قياس تأثير العنصر البشري على نتائج المؤسسة، على المئى المدى القصير و البعيد

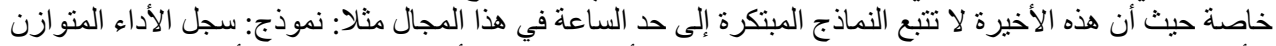

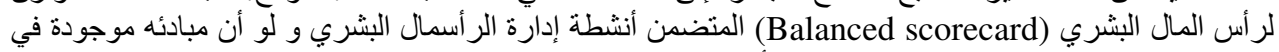

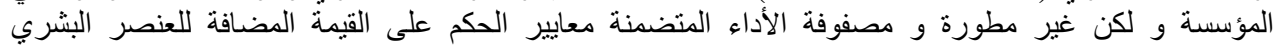
(الاكتساب، الانفاق، التطوير، الاحتفاظ) و أسس التقييم (التكلفة، الوقت، الكمية، الأخطاء و و رد الفعل بالنسبة للعمل بمعنى رضا العميل. و صعوبة رؤية تأثير الموارد البشرية على استر اتيجية المنظمة بالعين المجردة.

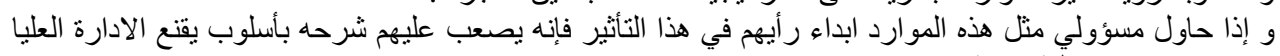
في غياب نماذج عملية متبعة.

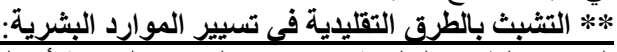

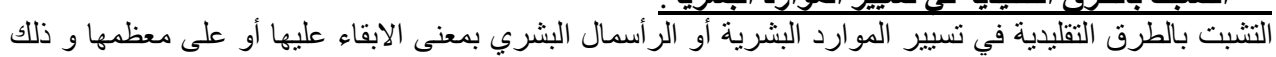

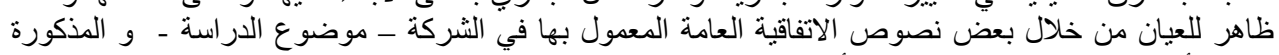

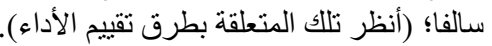

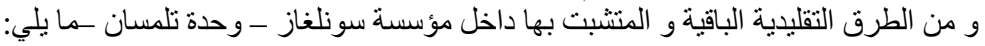

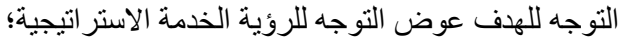

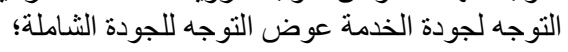

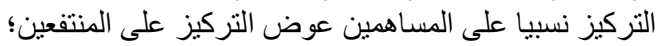

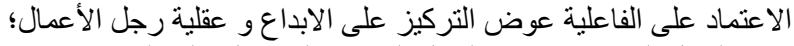

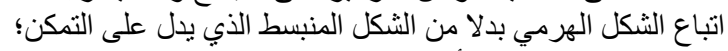

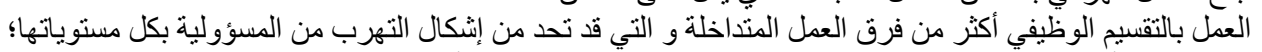

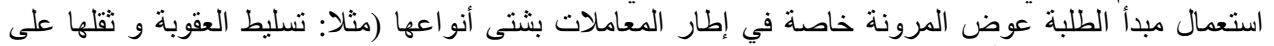

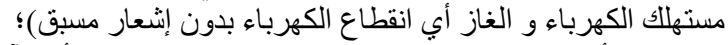

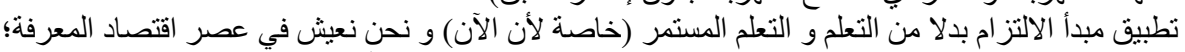

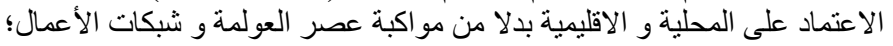

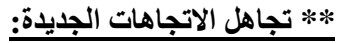

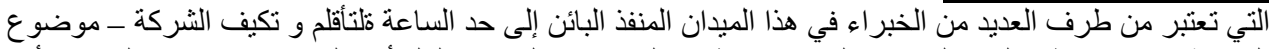

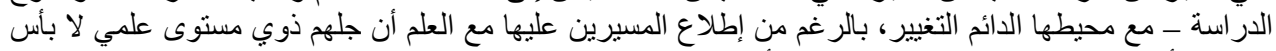

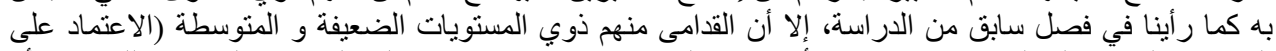

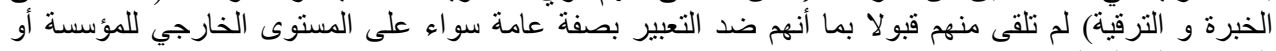
المستوى الداخلي لها. و من أهم هذه الاتجاهات ما لهائي:

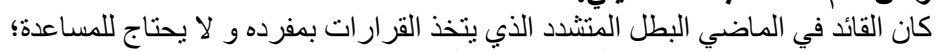

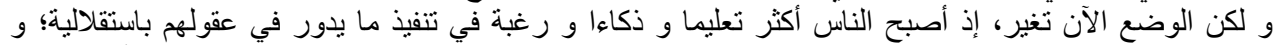

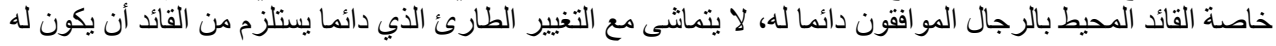


محيط مليء بالأقوياء و الأذكياء و ذوي العقول المتفتحة من العاملين، إذ نحن في عصر القيادة بالقيم و الثخصية و

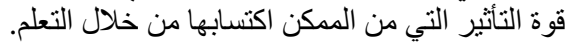

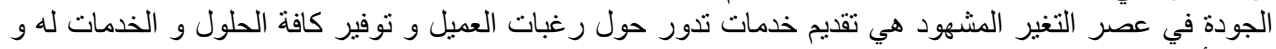

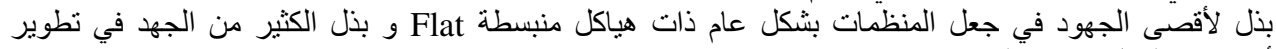

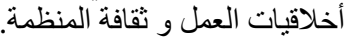

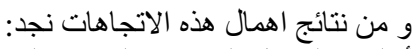

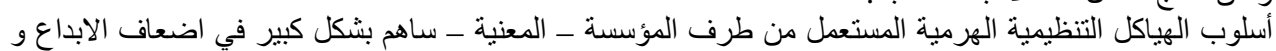
الابتكار بأثكاله الفردي و النظئ الجماعي.

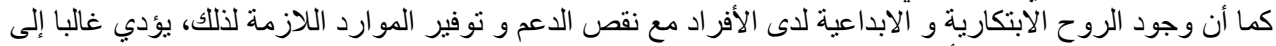

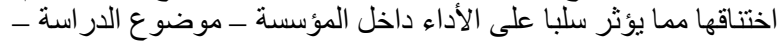

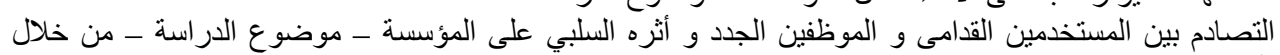
تأثثيره على محيط و ظروف التف العمل داخلها. اتخاذ الحلول التقليدية يعني تجاهل البعد الاستراتيجي في حل بعض التهل المشاكل التهل الخاصة بتسيير الموارد البشرية؛ مثلا:

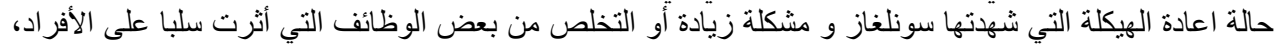

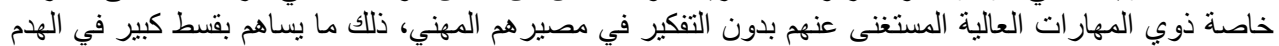

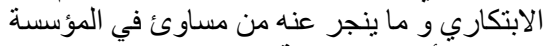
2-2-1 منها الاقتصاد المغلق أو المخطُة المخط و ما انجر عنه من استر اتجيات و سياسات (نقص التوظيف، الاستخدام عن طريق

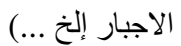
و مع تأرجح الوضع في البلد بين الاستقرار السياسي و عدمه و مع ظهور موجات غضب كثيرة عبر العالم (الربيع

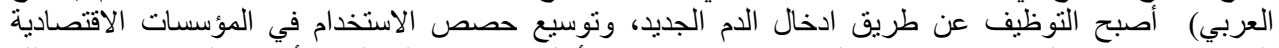

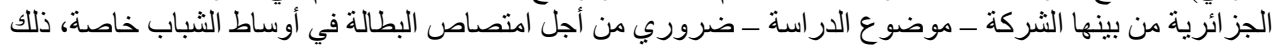

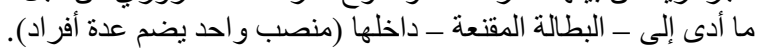

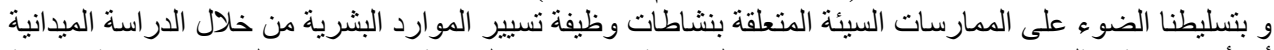

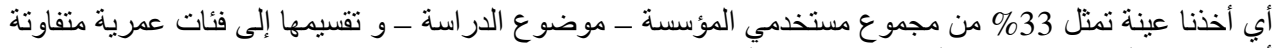

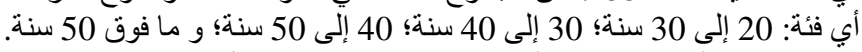
و تقتسيم هذه الفئات بدور ها إلى ذكور و إلى إناث و باستعمال تدرج "Likert")، ليكارث في الاستقصاء، اعتمادا على الصيغة التي تضمنت الخيار ات المو الية:

$$
\begin{aligned}
& \text { موافق بشدة، موافق، محايد، غير موافق، غير موافق بشدة. } \\
& \text { أو بؤ بوان }
\end{aligned}
$$

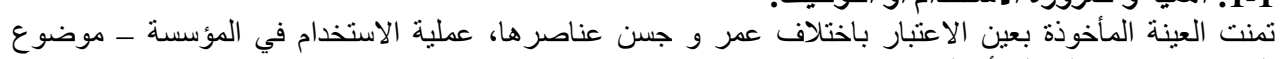

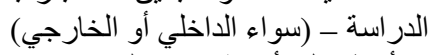
و أعطت لها أهمية كبيرة، لما تجنبه من آثار الثار ايجابية على كل المستويات (الفرد، الثركة و الدولة). ذلك ما أوضحناه من خلال الجداول و الأشكال المو الية: 
The reality in human capital.....

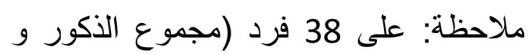

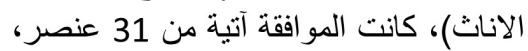

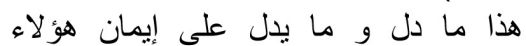
بتوظيف الأفراد و و تأثيره الايجابي على على الايكان

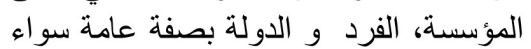

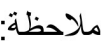

أخذنالمو افقةحيز اكبير افياجاباتهذهالفئة، إلأنحا

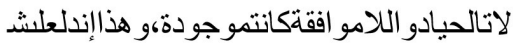
يء،فإنهيدلعلنتمسكهذهالفئتبالاستقر ار الوظيفي لإني

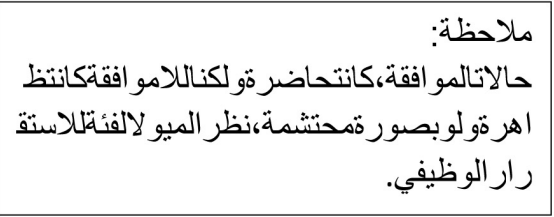

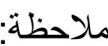
المو اققةكانتقائمةقو لكنالحيادكانموجو دا،

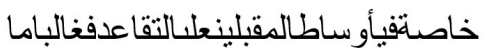
يميلو نإلسالسكونو هذالأسبابمتنو عة،قدنك و نعدمالر ضـا،و بالتاليعدمالا هتمادبمسار
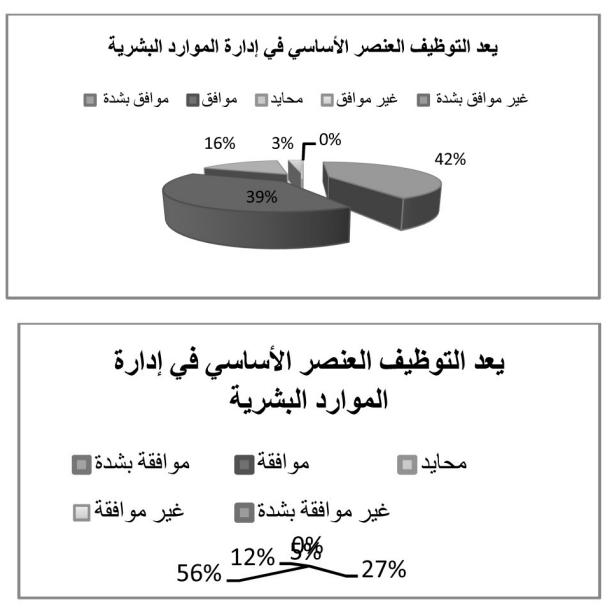

\begin{tabular}{|c|c|c|}
\hline \multicolumn{3}{|c|}{ لد التوظيف العنصر الأساسي في إدارة } \\
\hline مو افق بشدة" & موافقص & محايده \\
\hline غير موافق & \multicolumn{2}{|c|}{ غير مو افق بثدة" } \\
\hline $11 \% \_13 \%$ & & $20 \% 56 \%$ \\
\hline
\end{tabular}

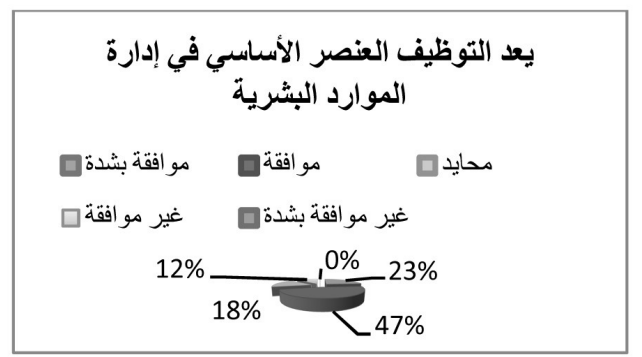

و لكن بالرغم من اعطاء هذه العملية الأهمية و التقاير من طرف كل الفئات المستجوبة ذكورا و إناثا إلا أن اهماله

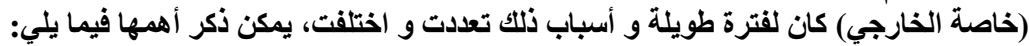

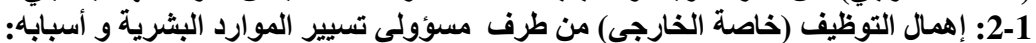

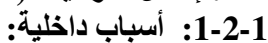

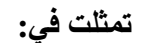

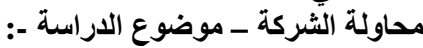

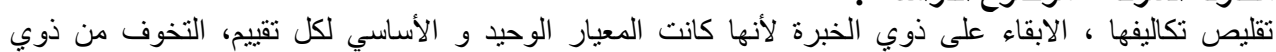

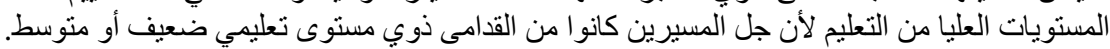
2-1 - 2-1 - 2-1 أسباب خارجية: منها الاقتصاد المغلق أو المخطط و ما انجر عنه من استراتجيات و سياسات (نقص التوظيف، الاستخدام عن طريق

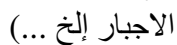
و مع تأرجح الوضع في البلد بين الاستقرار السياسي و عدمه و مع ظهور موجات غضب كثيرة عبر العالم (الربيع

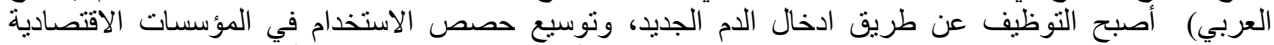

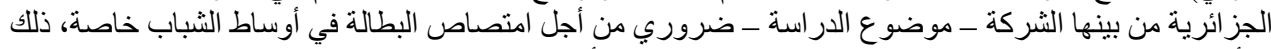

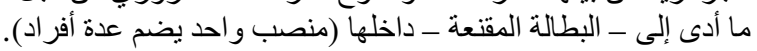




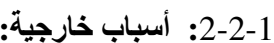

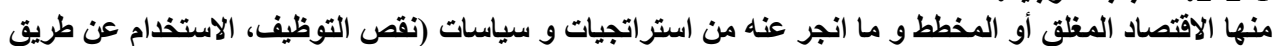
الاجبار إلخ ...)

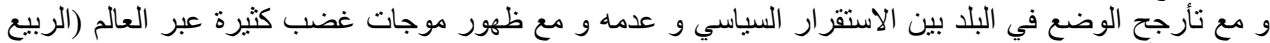

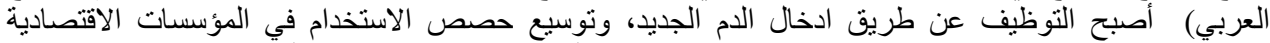

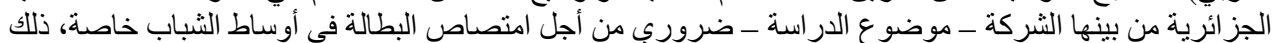

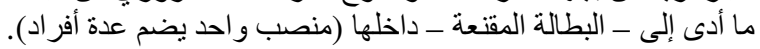

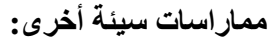

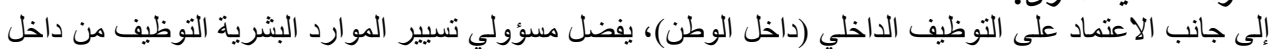

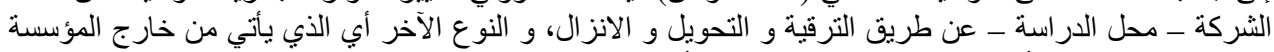

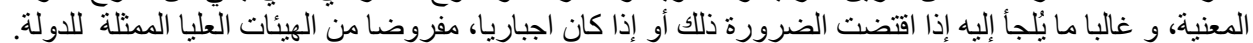

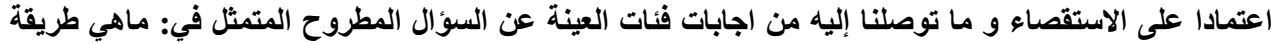

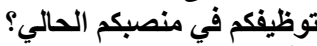

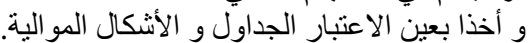

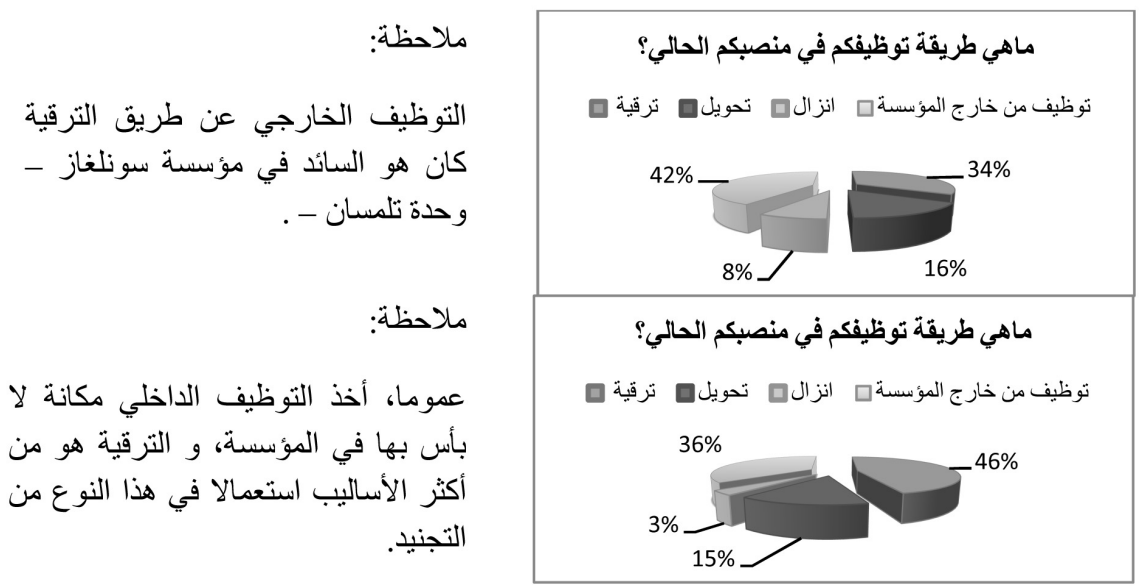

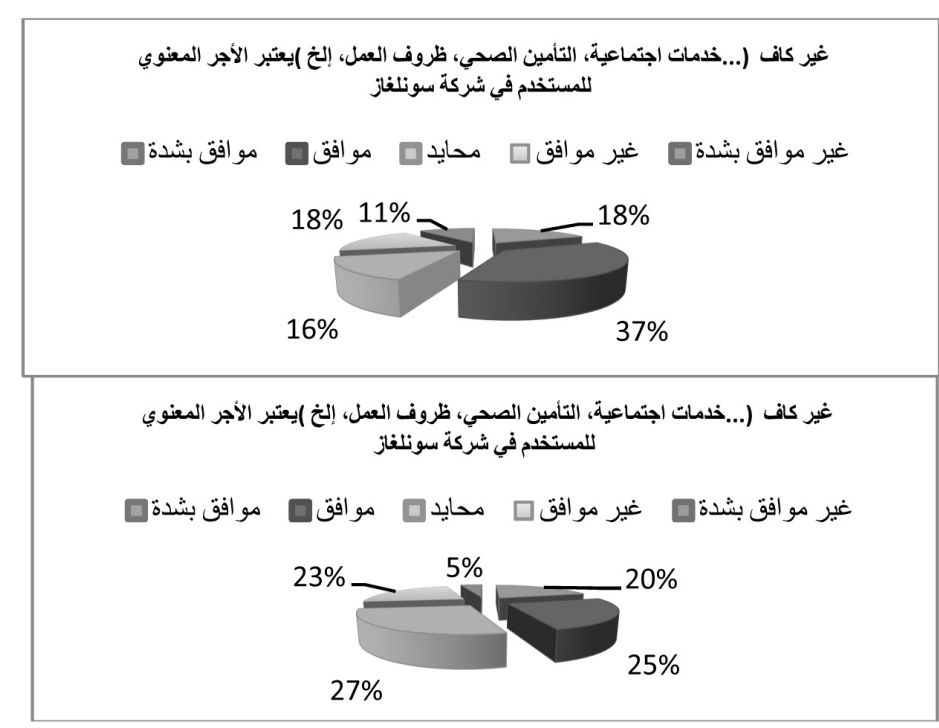


The reality in human capital.....

نجد أن التوظيف من داخل الثركة - موضوع الدر اسة ـ ما زال قائما و بنسب لا بأس بها، خاصة بطريقة الترقية، و

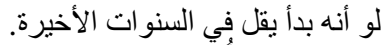

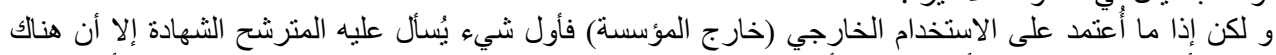

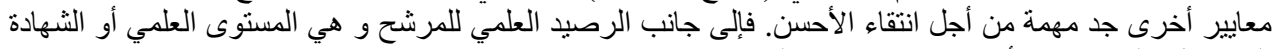

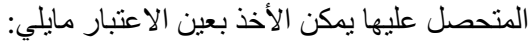
*** ذكاء المرشح و هي مدى قدرة المرشح على حلى حل المشاكل التي تعترض طريقه في العمل و مدى قدرته على ابتكار حلول جديدة؛

*** خبرة المرشح و هي الرصيد الذي يملكه المرشح من خبرته في العمل أو خبرته الحياتية؛

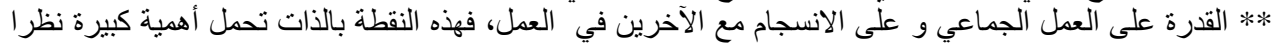

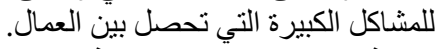

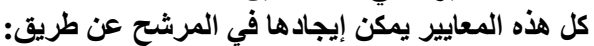

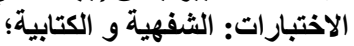

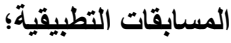

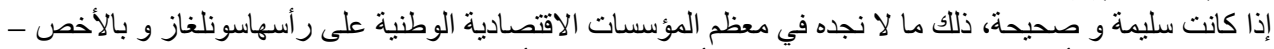

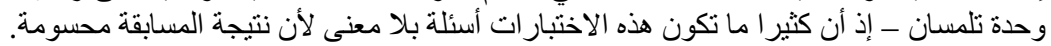

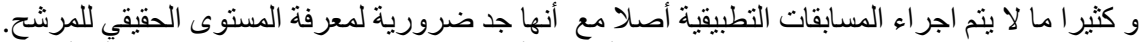

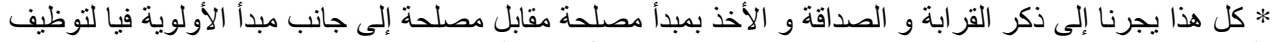

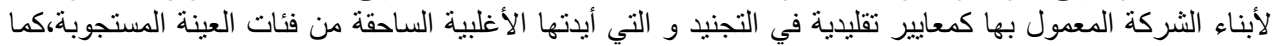
تبينه الأشكال و الجداول المعول بها كوالية

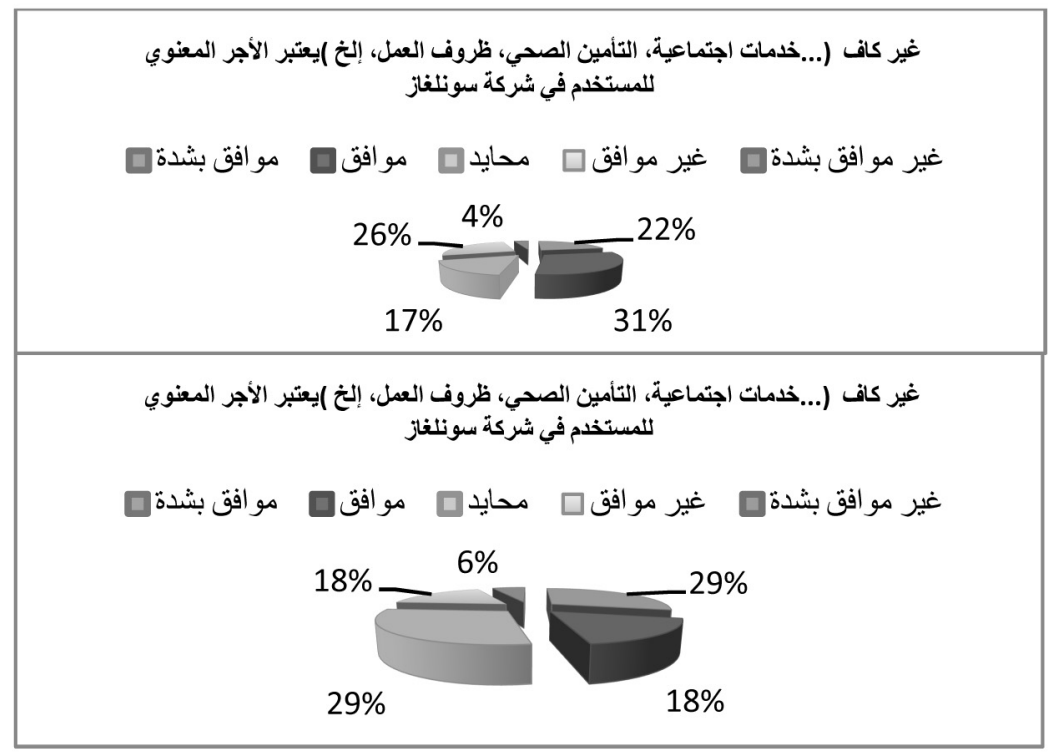

20132 المصدر:الاعداد الثخصي 


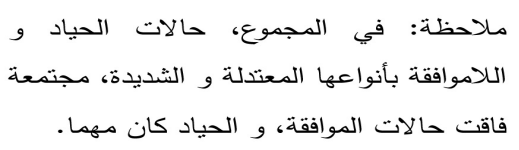

2- الأجر:

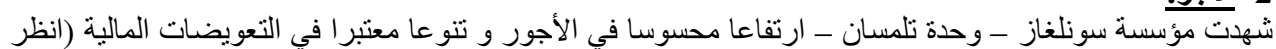

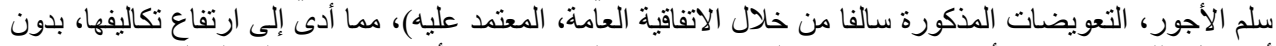

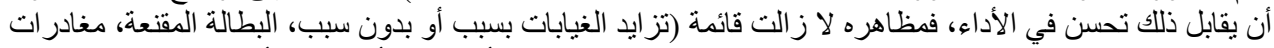

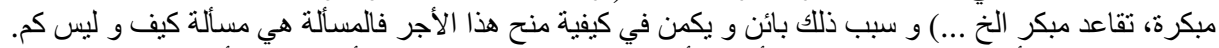
فحسب العينة المأخوذة بعين الاعتبار، أغلب أعضائها راضئ راضون على فلى الكم أي على الأجور و ملحقاتها المادية (تعويضات مكافآت) دون الكيف. الكين.

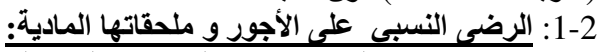

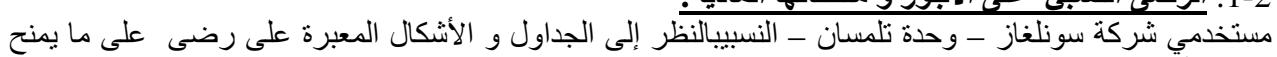

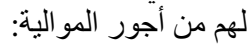


The reality in human capital.....

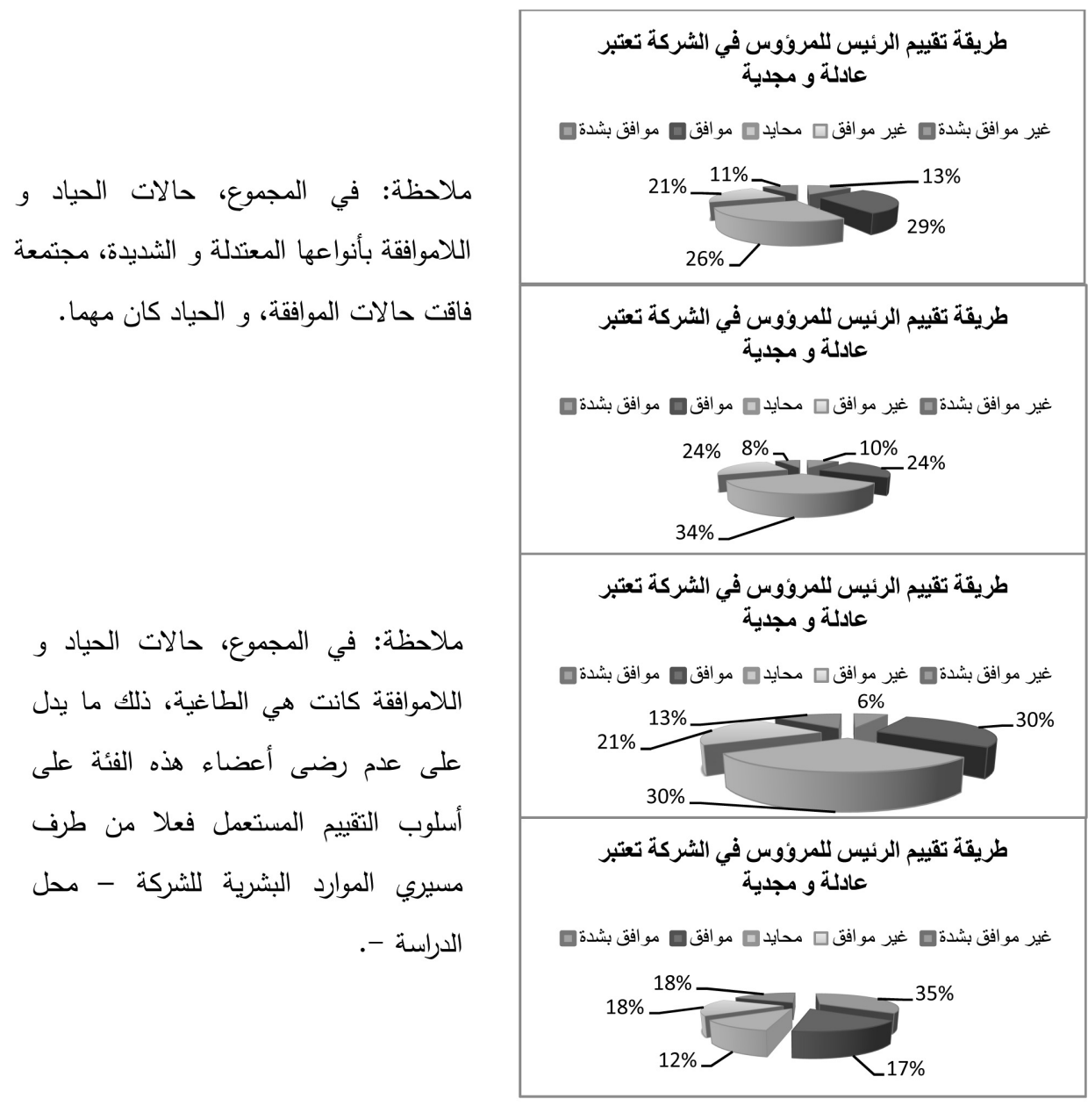

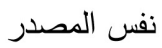

المصدر الاعداد الثخصي 2013 
الملاحظة العامة:

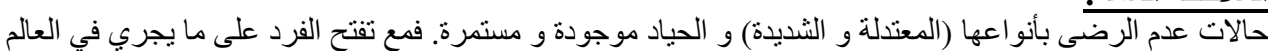

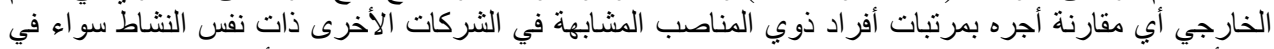

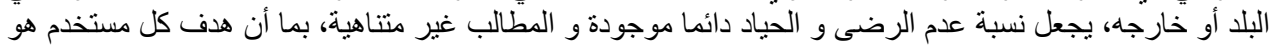
الحصول على أعلى أجر مدكن.

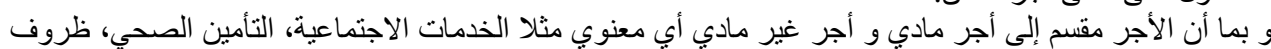

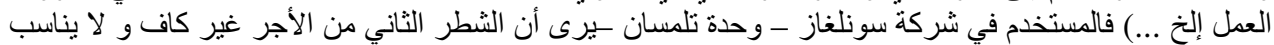
منصبه مما يؤثر سلبا على أُّائه.

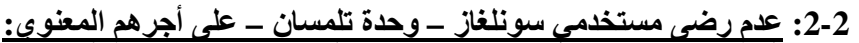

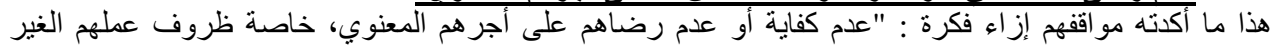

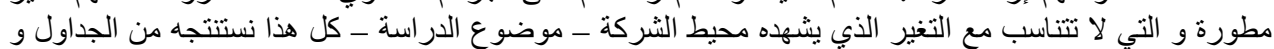

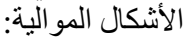
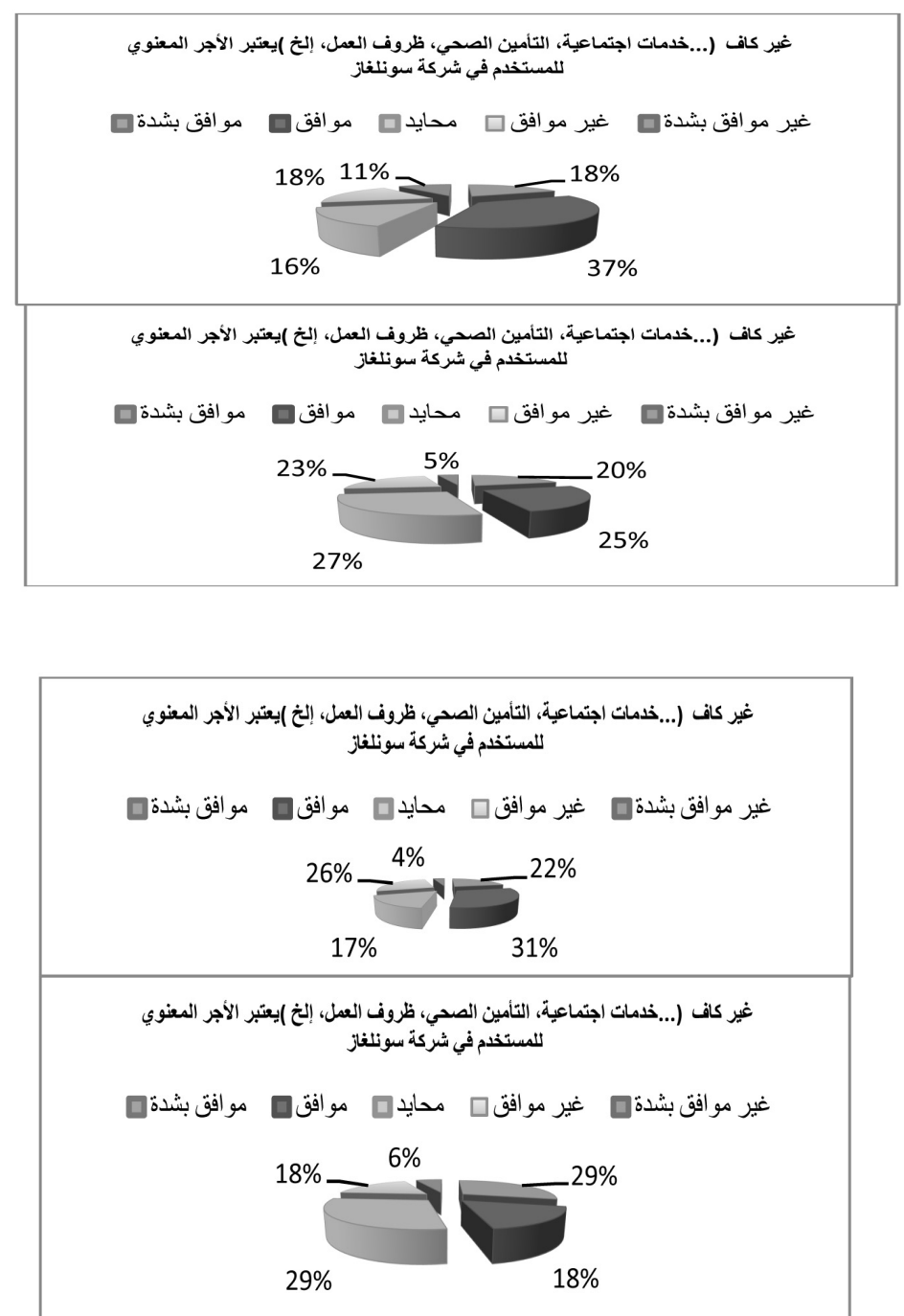

المصدر:الاعداد الثخصي 2013 


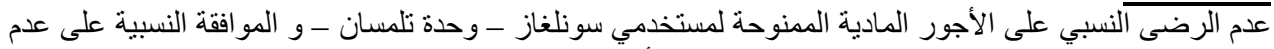

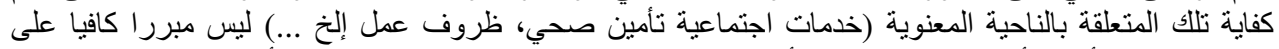

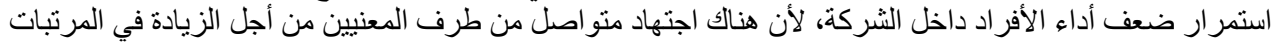

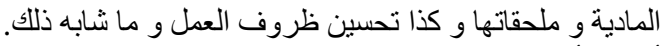

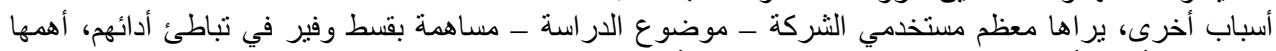
عملية تقييم أداء الأفر اد المعتمد عليها في نشاطي دفي الأني الأجر و التكوين. * تقييم الأداء:

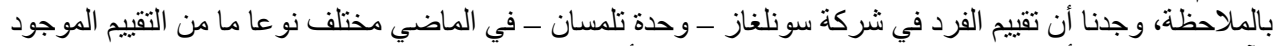

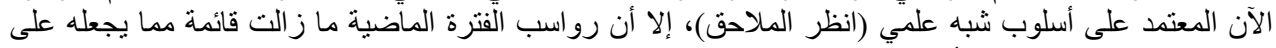

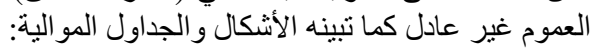

نفس المصدر

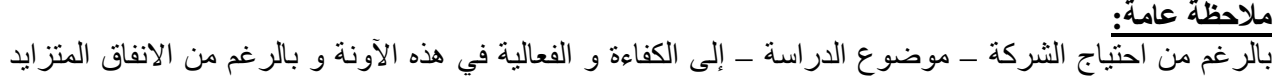

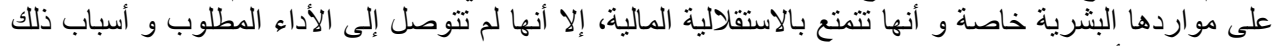
يمكن تلخيص أهمها فيمايلي:

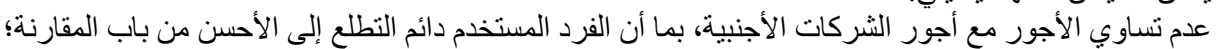

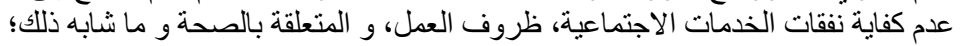

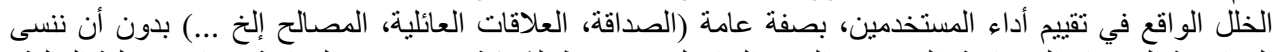

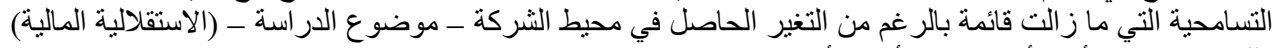

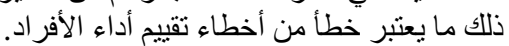

كل هذه الثوائب قد تؤدي إلى مظاهر الأداء السيء المتمثلة في الغيابات بأنواعها، النزاعات، اللامبالات، الخئ...).

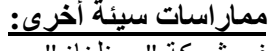

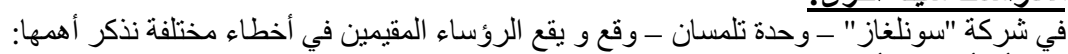

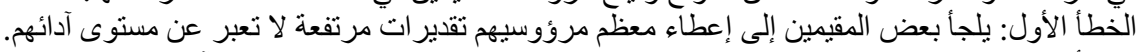

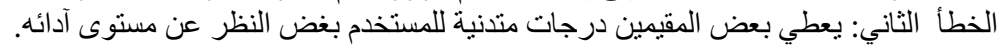

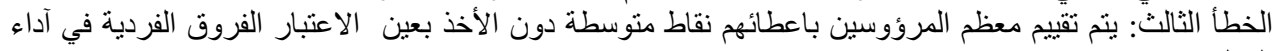
العمل. (الخط.

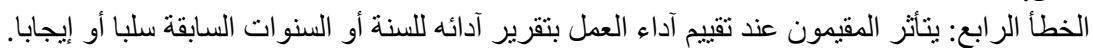

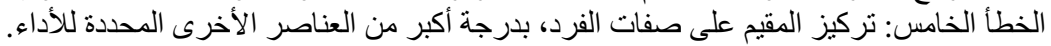

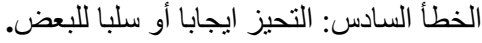

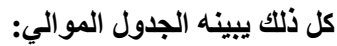
نسب المو افق المتخذة تجاه بعض الجول أخطاء الرؤساء افي تقييم مرؤوسيهم. 
Journal of Business \& Management (COES\&RJ-JBM), 5(2), pp. 102-130

\begin{tabular}{|c|c|c|c|c|c|c|}
\hline المجموع & غير موافق بشدة & غير موافق & محايد & موافق & موافق بثدة & أخطاء المقيم \\
\hline & التكرار & النكرار & التكرار & التكرار & التكرار & الخطأ الأول \\
\hline \multirow[t]{2}{*}{189} & 49 & 40 & 15 & 40 & 45 & \\
\hline & النسبة & النسبة & النسبة & النسبة & النسبة & \\
\hline \multirow[t]{2}{*}{$\% 100$} & $\% 26$ & $\% 21$ & $\% 8$ & $\% 21$ & $\% 24$ & \\
\hline & التكرار & التكرار & التكرار & التكرار & التكرار & الخطأ الثاني \\
\hline \multirow{2}{*}{189} & 60 & 70 & 10 & 35 & 14 & \\
\hline & النسبة & النسبة & النسبة & النسبة & النسبة & \\
\hline \multirow[t]{2}{*}{$\% 1000$} & $\% 32$ & $\% 37$ & $\% 5$ & $\% 19$ & $\% 7$ & \\
\hline & التكرار & النكرار & التكرار & التكرار & النكرار & الخطأ الثالث \\
\hline \multirow[t]{2}{*}{189} & 45 & 65 & 05 & 39 & 35 & \\
\hline & النسبة & النسبة & النسبة & النسبة & النسبة & \\
\hline \multirow[t]{2}{*}{$\% 100$} & $\% 24$ & $\% 34$ & $\% 3$ & $\% 21$ & $\% 18$ & \\
\hline & التكرار & النكرار & التكرار & التكرار & النكرار & الخطأ الرابع \\
\hline \multirow[t]{2}{*}{189} & 42 & 50 & 12 & 45 & 40 & \\
\hline & النسبة & النسبة & النسبة & النسبة & النسبة & \\
\hline \multirow[t]{2}{*}{$\% 100$} & $\% 24$ & $\% 34$ & $\% 3$ & $\% 24$ & $\% 21$ & \\
\hline & التكرار & التكرار & التكرار & التكرار & التكرار & الخطأ الخامس \\
\hline \multirow[t]{2}{*}{189} & 13 & 35 & 20 & 65 & 56 & \\
\hline & النسبة & النسبة & النسبة & النسبة & النسبة & \\
\hline \multirow[t]{2}{*}{$\% 100$} & $\% 7$ & $\% 19$ & $\% 10$ & $\% 34$ & $\% 30$ & \\
\hline & التكرار & التكرار & التكرار & التكرار & التكرار & الخطأ السادس \\
\hline \multirow[t]{2}{*}{189} & 30 & 40 & 14 & 55 & 50 & \\
\hline & النسبة & النسبة & النسبة & النسبة & النسبة & \\
\hline$\% 100$ & $\% 16$ & $\% 21$ & $\% 7$ & $\% 29$ & $\% 27$ & \\
\hline
\end{tabular}

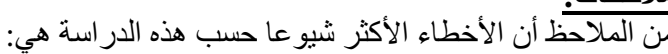
تركيز المقيم على صفات الفردة، بدرجة ألكبر من العناصر الأخرى المحددة للأداء؛

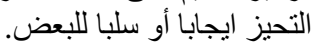

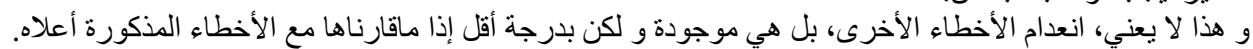

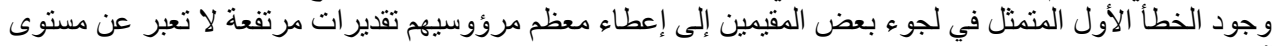

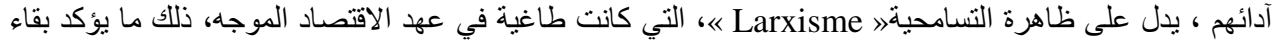
رواسب النظام الاقتصادي السابق في المؤسسات الاقتصادية الجزائرية عامة و شركة سونلغاز - وحدة تلمسان ـ لـان

بغياب وظيفة خاصة بالتتمية البشرية ماز الت إدارة تسيير الموارد البشرية في شركة سونلغاز - وحدة تلمسان - تباشر نشاط النكوين و التنريب مثله مثل النشاطات الأخرى السالفة الذكر (توظيف، أجر ) في إطار وظيفة تسيير الموارد 
The reality in human capital.....

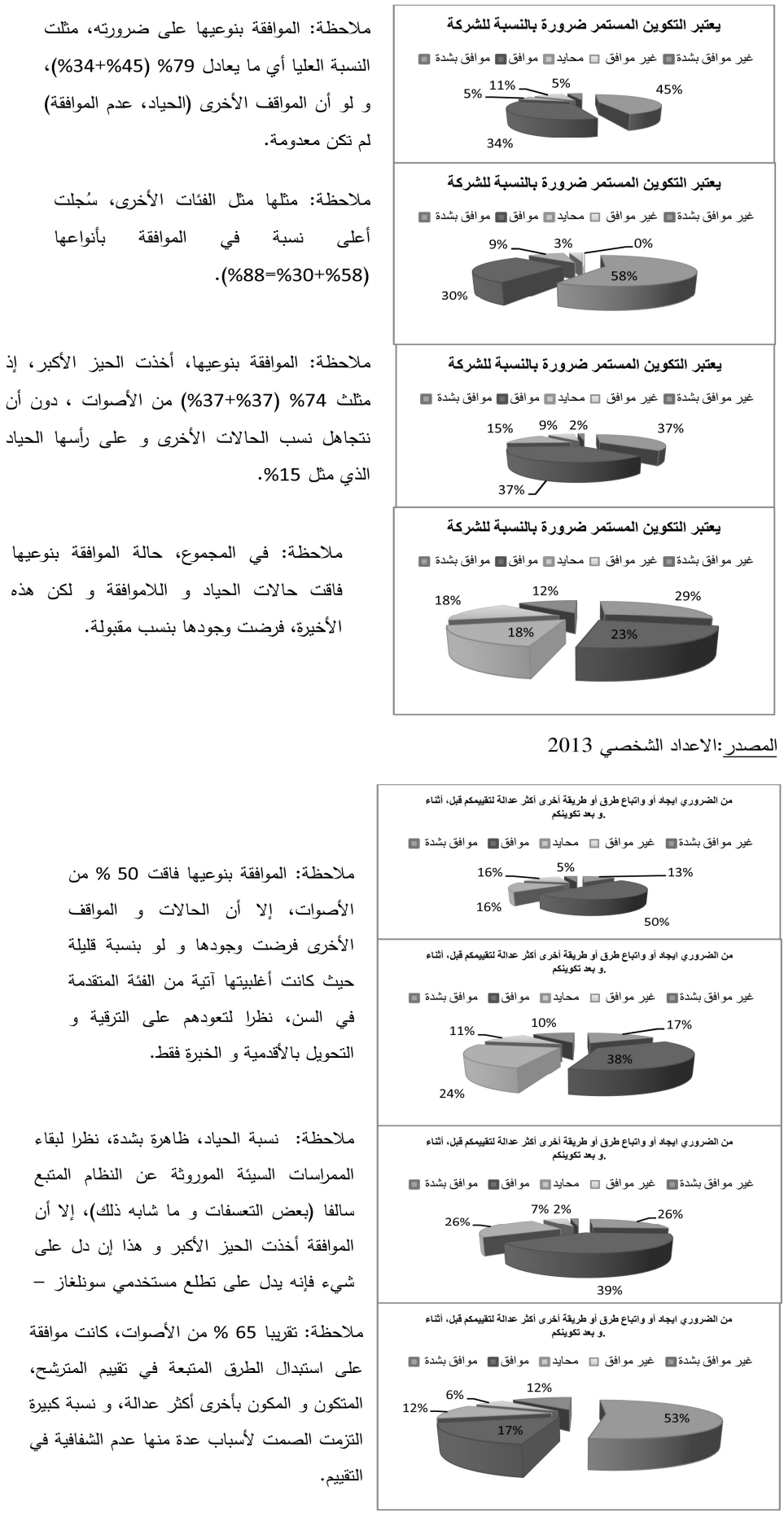




$$
\begin{aligned}
& \text { ملاحظة: في المجموع، انعدم } \\
& \text { التكوين الخارجي و تفوق التكوين } \\
& \text { الداخلي مع بقاء بعض العناصر } \\
& \text { محرومة منـه. }
\end{aligned}
$$

ملاحظة: في المجموع، نلاحظ انعدام التكوين

$$
\text { الخارجي. }
$$

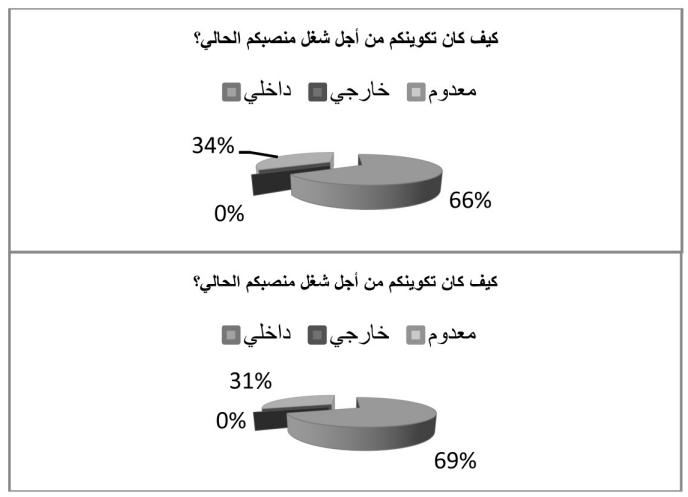

ملاحظة:

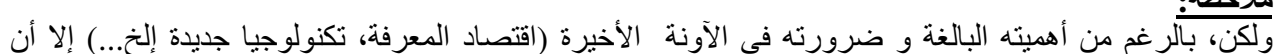

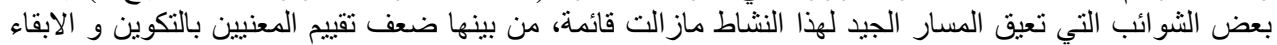

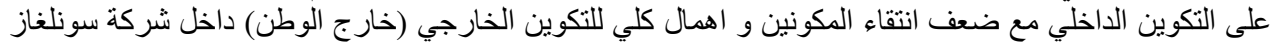

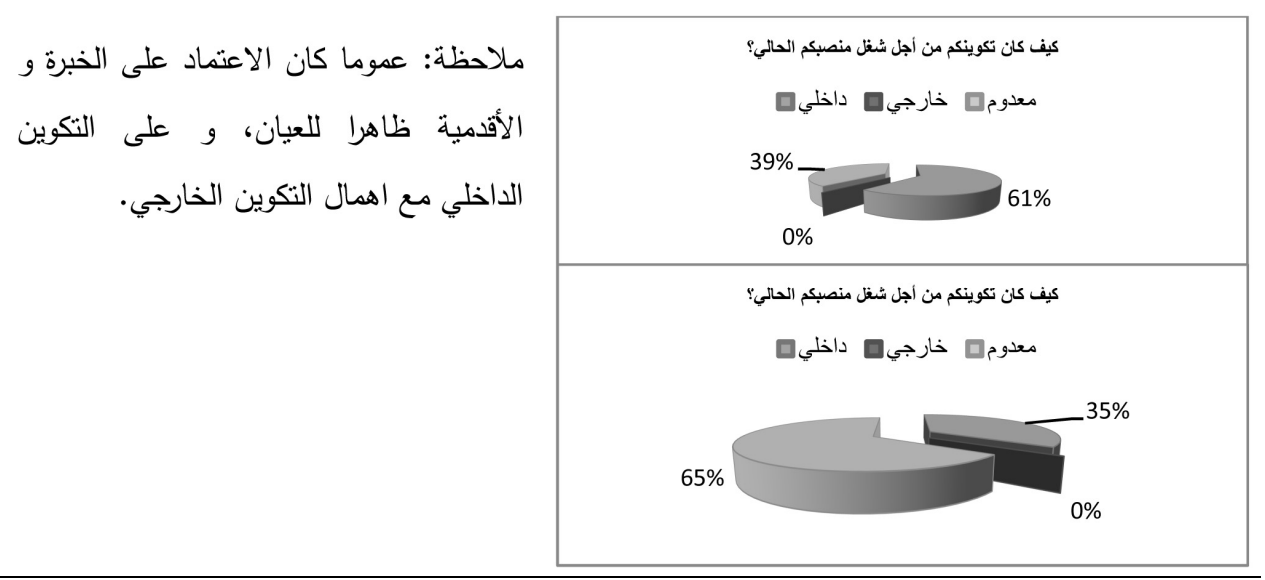

المصدر: الاعدادالثخصي2013 ملاحظة:

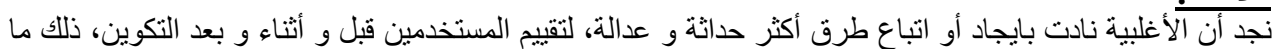

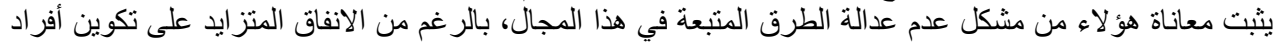

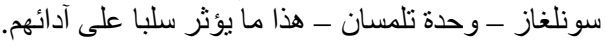

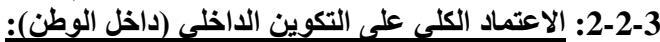

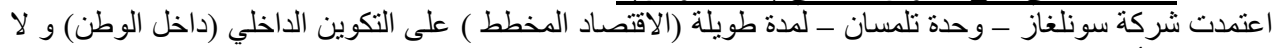

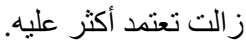

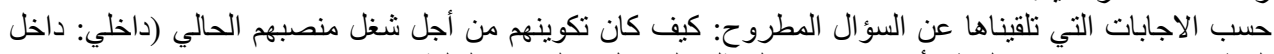

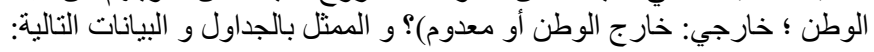

ملاحظة: 


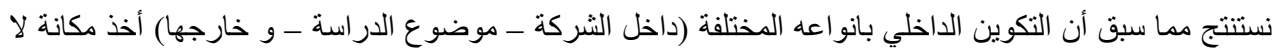

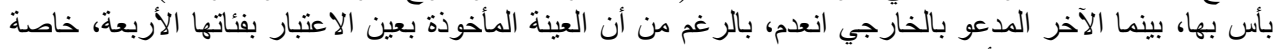

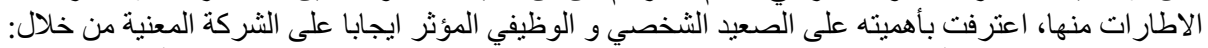

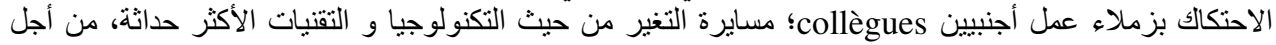

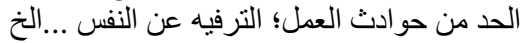
زيادة على ذلك، كانت طرق النتقاء المكونين ثقليدية بمعنى الاعتماد بالدرجة الألى الأولى على أقدمية و خبرة المستخدم

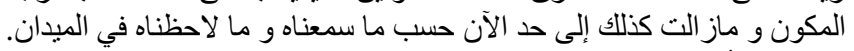

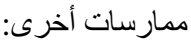

غالبا ما يفضل مسؤولو تسيير الموارد البشرية في مؤسسة سونلغاز - وحدة تلمسان - التكوين الداخلي التقني و بعيدا

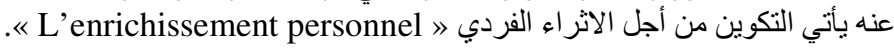

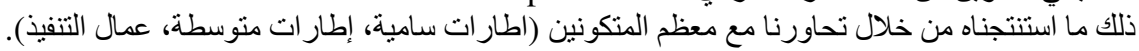

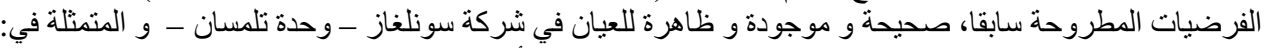
افتقار وظيفة تسيير الموارد البشرية للبعد الاستراتيجي في ادارتها للتر أسمال البثري.

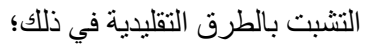

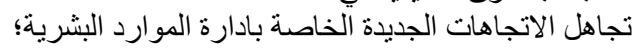

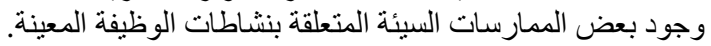

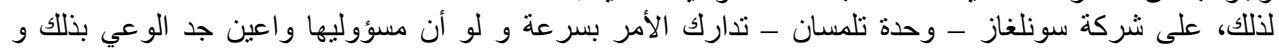

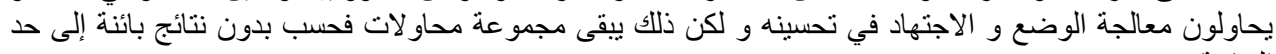
الساعة. و للتخفيف من وطأة هذه الإثكالية على مؤسسة سونلغاز - وحدة تلمسان - تقتر ح ما يلي:

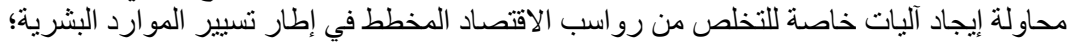

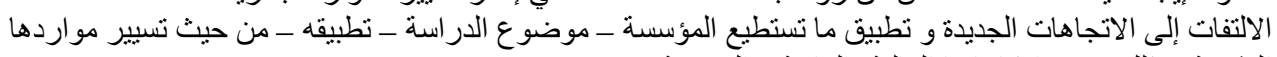
البشرية و ذلك حسب إمكانياتها المالية، المادية و المعنوية؛

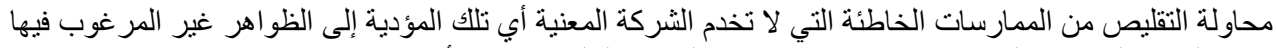
(مثلا الغياب المتكرر، المغادرة، انخفاض الإنتاجية...الخ) و بالتالي ضعف الأداء.

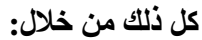
التخلي عن العادات السيئة في التوظيف (العلاقات العائلية، الصداقات، الخدمات المتبادلة ... الخ)، و تغلب مبدأ الكفاءة

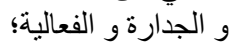

الاعتماد على التخطيط حسب أهداف المؤسسة - موضوع الدراسة - في مجال تسيير الموارد البشرية خاصة

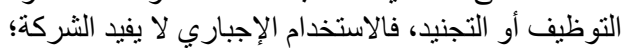

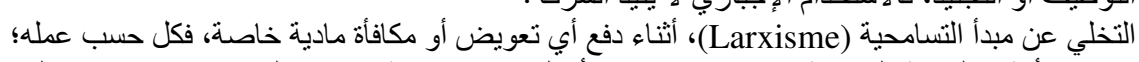

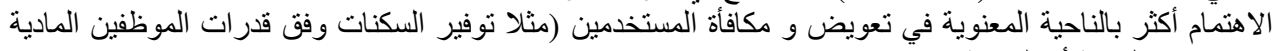

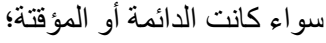

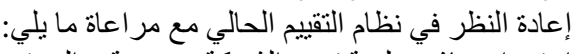

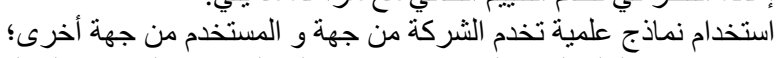

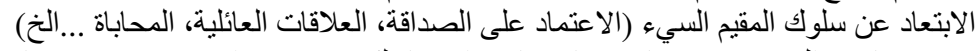

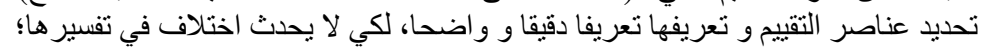

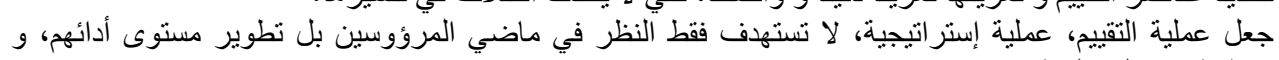
تخطيط مستقبلهم الوظيفي؛

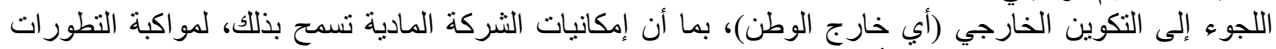

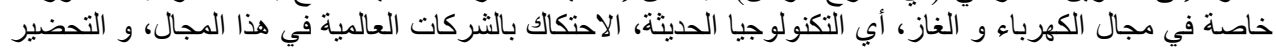

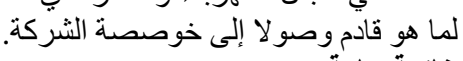

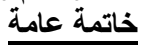

يعد الفرد موردا استراتيجيا و قدرة فكرية و مصدر للمعلومات و الابتكار ات، تعمل المؤسسات الاقتصادية على تثمينه

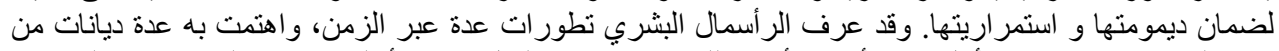

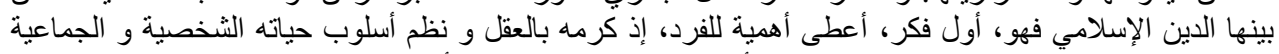

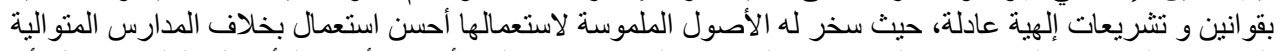

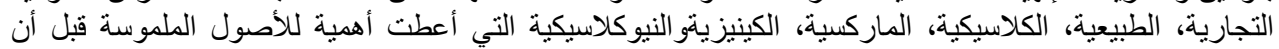

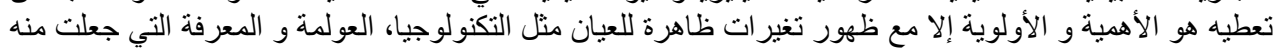

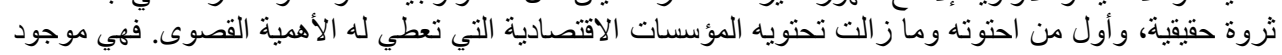




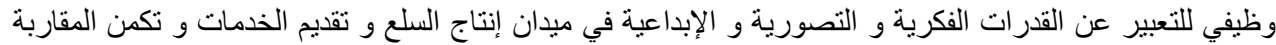

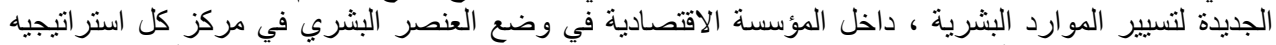

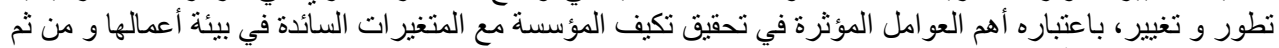
قدرنها على تحقيق أهدافها المحددة.

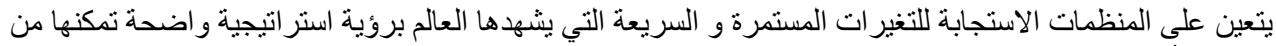

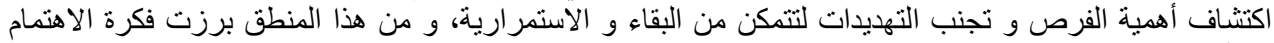
بالر أسمال البشري و الاستية الفرصنمار فينه.

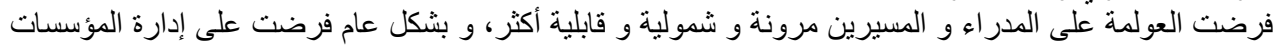

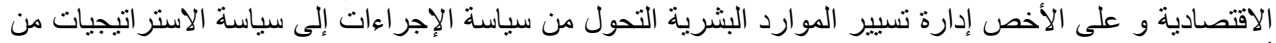
أجل البقاء و الاستمر ارية.

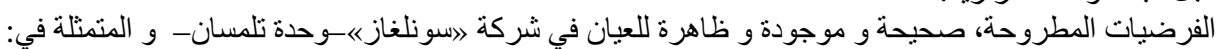

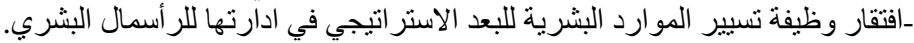

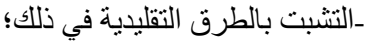

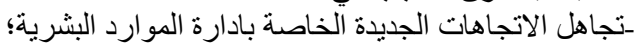

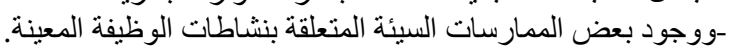

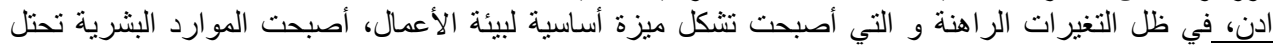

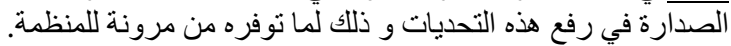
و من ثم، أضحت النظرة إلى المورد البشري مختلفة عمّا كانت عليه في المّانة الماضي (تكلفة)، إذ تحول إلى:

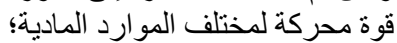

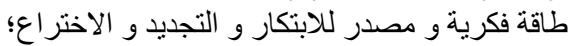

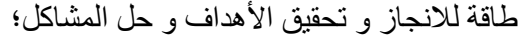

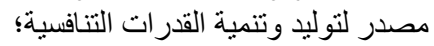
قوة لافع و تفعيل التغير؛

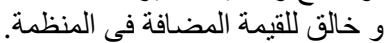
أما النظرة لإدارثنه، اختلفت عما كانت الته عليه، فهي الآن:

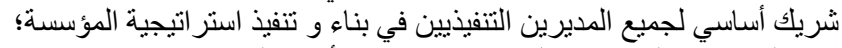

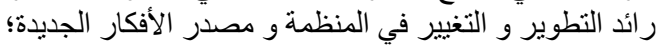

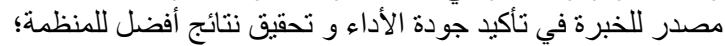

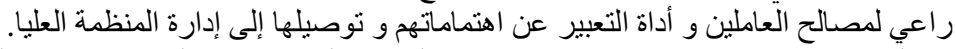

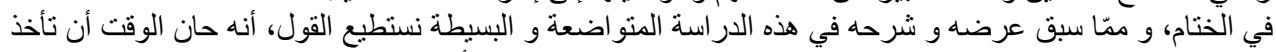

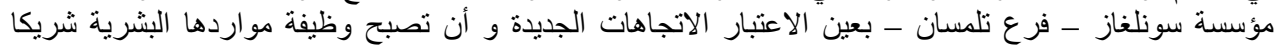

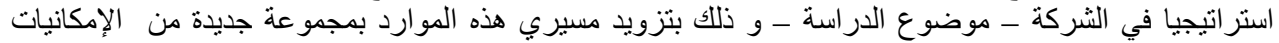

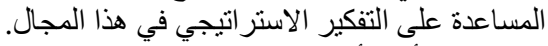

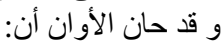

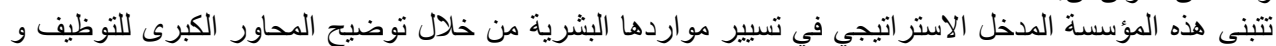

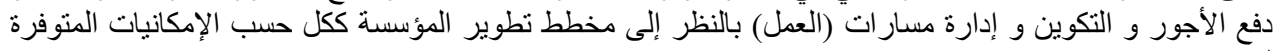

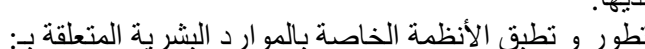
نظام الاستقطاب و الاختبار و التعيين (التوظيف) نظام الأجور و الامتياز الات

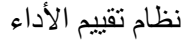
نظام الترقية نظام أخلاقيات و آداب المهنة

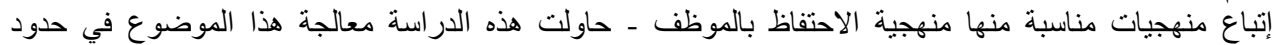

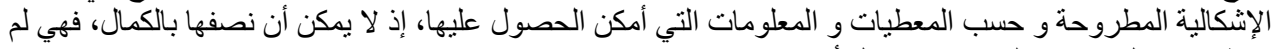
تحظ حتما بكل جو انب الموضوعة و و بكل أبعاده. 


\section{References}

- Human resource, capital of cognitive most prized in the Arab country, a lecture prepared by trustee ImadEddin February 2004.

- Abdul QadirJglol: social scientist of the most important writings in the field of historical dilemmas of political sociology at the IbnKhaldun.

- Ali peaceful of his works include Introduction to Behavioral Sciences in 1969, personnel management in 1970 to raise production efficiency, human behavior in management in 1973, and behavioral systems in 1978.

- Ahmed Ta'ani: His other books mention the most important: management training according to the vision developmental training: concept and its effectiveness, build a training and evaluation programs.

- Documents of internal organization with the setup Profile 2011-2012-2013

- The Limitations of Marginal Utility", (First Published 1909), in: The Place of Science in Modern Civilization.

- The Preconceptions of Economic Science", (First Published 1900) in: The Place of Science in Modern Civilization.

- A. khemakhem, the dynamics of question control, Dunodparis, 1977.

- A. Chandler, Strategy and Structure, M.I.T press, London, 1962.

- ABDELADIM Leila: The privatization of public enterprises in the Maghreb countries, international editions, Paris 1998.

- Alain -Charles Martinet Ahmed, lexicon of management, 7 edition, 2005, Dalloz,.

- ANDRE BOYER, the essentials of management, Paris, Edition d'organization, 2001.

- Anne-Marie FERICELLI and Bruno SIRE, Performance and Human Resources, econnomica 2002.

- Ardouin Thierry, \{Formation Engineering for Enterprise\}, Ed Dunod, paris, 2003.

- Armand Dayan, Management Manual, ELLIPSES, AUF, Paris, 1998

- BERNARD Colas, Encyclopedia of Accounting. Management Control and Audit, Economica, 2000.

- Bernard MAR tory, Daniel Crozet, human resources management, 4 editions dunod, paris, 2001,

- Bernard Martory and Daniel Grazet, Human Resources Management: Social Leadership and Performance, Dunod, Paris, 2001.

- Bertrand Thiery and others, Organization and management of the company, éditionsd'Organization, Paris, 3rd ed, 1998.

- Charles-Henri Bessetre Des Horts, Managing Human Resources in Business: Concepts and Tools, Organizational Editions, Paris, 1990,

- Curle Adam, Educational strategy for developing societies, Tavistock publication limited, London, 1963.

- David Schweickart, Against capitalism. Boulder, Colorado: Westview Press, 1996.

- Elie Cohen, dictionary of management, edition the discovery paris 2000.

- Emanuel Carre, Alain Labruffe, \{Guide to New Trainer) Talent in Practice (AFNOR Edition, 2006.(

- Eric Vatteville. Measurement of human resources and management of the company, Economica, Paris, 1985.

- Gorouitz Elizabeth, "Employee Training Current Trends," Future Challenges, Training and Development Journal, August 1993

- Stop the mess ! IH Ansoff, Corporate Strategy, New York, Mc-Graw-Hill Book commpany, 1965. 
- Investments and Development: Systemic Approach International Colonial Communications: Evaluation of the effects of public investment programs 2001-2014 and their impact on employment, investment and economic growth, Dr. Aoumeur AKKI ALOUANI Associate Professor, University of Setif I, March 11-12, 2013

- ISHIHARA KATSUYOSHI "Maitising quality management methodology", editions MARE NOSTRUM, 1996.

- J. Dilauro. Training needs assessment: current practice and new directions $>$. Public personal management. Nov.Dec. 1994

- J.C Barbie, the organization of work. Paris. The sycamore. 1982J. Butler, G.R. Ferris and N.K. Napier, Strategy and Human Resources Management, Cincinnati, South Western and Dyer, 1991 Jean Aubert, Corporate Strategies: From Patrimonial Development to Partnership, "Liaison Editions, Paris, 1995, JM.PERETTI, \{Human Resources and People Management\}, 4th ed. Ed Vuibert, Paris 2002

- Karl Marx, "Wage Labor and Capital", in Karl Marx and Frederick Engels, Selected Works, vol. I. Foreign Languages Publishing House, Moscow 1955. Karl Marx, Grundrisse. Foundations of the Critique of Political Economy. Translated by Martin Nicolaus, Penguin Books, Harmondsworth, Middlesex 1993.

- Klaus H. Hennings, the Austrian Theory of Value and Capital. Studies in the Life and Work of Eugen Von Bohm-Bawerk. Edgar Elagar, Chaltenham UK, Brookfield US, 1997

- L. Béanger et al, Strategic Management and Human Resources Operations, Gaeton Morin, Chicoutimi, 1999 Economic Reform in Algeria 